\title{
DERECHO Y ECONOMÍA
}

HAY UNA GRAN DIFERENCIA ENTRE MEDIOS Y FINES. EL RECONOCIMIENTO del papel de las cualidades humanas como motor del crecimiento económico no aclara cuál es la meta del crecimiento. Si, en último término, el objetivo fuera propagar la libertad para tener una vida digna, el papel del crecimiento económico consistiría en proporcionar mayores oportunidades para ello y debería integrarse en una comprensión más profunda del proceso de desarrollo.

Amartya Sen, "Las teorías del desarrollo a principios del siglo XXI", Cuadernos de Economía, Universidad Nacional de Colombia, No. 29, p.89

Los servicios públicos domiciliarios y el Estado regulador, Everaldo Lamprea Montealegre

Los derechos laborales en el tratado de libre comercio entre Colombia y los Estados Unidos, César A. Rodríguez Garavito

Law and Modernization, Richard Posner

Neoinstitucionalismo: en la encrucijada del proceso de apropiación por las ciencias sociales en Colombia, Jaime Eduardo Londoño Motta 



\title{
LOS SERVICIOS PÚBLICOS DOMICILIARIOS Y EL ESTADO REGULADOR ${ }^{1}$
}

\author{
EVERALDO LAMPREA M.
}

Economic regulation by the State is an alternative to reconcile the search for social welfare and equity with the efficiency of the market system. However, the excessive promulgation of norms by the State can end up being ineffective and create a crisis between the political and juridical system. This article explores this problem and proposes a research perspective on the subject, which focuses on the public services sector and gives priority to the perception of operators.

\section{Introducción}

Con objeto de entender las virtudes y contradicciones del modelo regulatorio, hemos decidido proponer el ejemplo de la regulación de servicios públicos domiciliarios en Colombia. Dentro de las diversas áreas de la economía reguladas por el Estado, los servicios públicos domiciliarios constituyen un ejemplo excepcionalmente interesante en tanto allí se entrecruzan claramente el concepto de Estado Social de Derecho con el de mercado. Este caso particular de regulación constituye un entorno privilegiado para estudiar las tensiones entre un Estado Social de Derecho que pretende materializar sus principios a través de la prestación efectiva y equitativa de los

\footnotetext{
${ }^{1}$ El presente ensayo es el producto de la investigación desarrollada en el Centro de Investigaciones Sociojurídicas (CIJUS) de la Facultad de Derecho de la Universidad de Los Andes, con apoyo de la Beca Jóvenes Investigadores de Colciencias, durante el año 2004. Agradezco los comentarios y sugerencias hechos a lo largo del proceso de investigación por el Profesor Daniel Bonilla. Agradezco además las críticas y recomendaciones hechas por los profesores presentes en el Seminario de Profesores (Facultad de Derecho, Universidad de Los Andes, febrero 2005), donde este texto fue presentado. El profesor Lelio Fernández (Universidad ICESI, Cali) hizo varias sugerencias a este texto, que intenté incorporar en esta versión final.
} 
servicios públicos domiciliarios, y un mercado de servicios públicos domiciliarios en el cual la iniciativa privada y la libertad de empresa buscan nichos de desarrollo. Consideramos que, en Colombia, el área de la regulación de los servicios públicos domiciliarios presenta muchas características interesantes para entender cómo el modelo regulatorio busca resolver las tensiones entre Estado Mínimo y Estado Máximo. También consideramos que el caso de la regulación de servicios públicos domiciliarios en Colombia presenta una serie de contradicciones y paradojas propias de la crisis del Estado regulador, las cuales vale la pena entrar a analizar. Fueron principalmente éstas las razones teóricas que nos llevaron a enfocarnos en la regulación de esta área en particular.

Desarrollaremos la argumentación del siguiente modo. En primer lugar, mostraremos por qué la intervención del Estado en la economía es necesaria ante las fallas que producen los mecanismos de mercado y ante las paradojas del Estado de Bienestar. Nuestra posición al respecto es que el modelo regulador es un modo de intervención en la economía que pretende evitar las paradojas del Estado Mínimo (Estado libertario o neoliberal) y del Estado Máximo (Estado de Bienestar), y optimizar al mismo tiempo los aciertos de ambos esquemas. Argumentaremos que en el entramado Constitucional colombiano la intervención del estado en economía no puede enmarcarse en esquemas maximalistas (Estado de Bienestar) o minimalistas (Estado neoliberal), sino en el esquema regulatorio, el cual busca combinar y optimizar elementos de ambos modelos. Sostendremos que nuestro modelo regulatorio resulta ventajoso ya que da suficiente cabida a la iniciativa privada y a la eficiencia económica, pero dentro del marco de regulación, control y vigilancia estatal, a través del cual se pretende dirigir los mecanismos de mercado hacia la consecución del bienestar y la equidad social. Son precisamente éstas las ventajas que ofrece el esquema de regulación estatal en la economía, y particularmente en el sector de los servicios públicos domiciliarios. Mostraremos que no obstante los logros de la regulación en esta área, se presentan serias deficiencias en la implementación del esquema regulador, las cuales son atribuidas, por una parte, a la influencia nociva del Gobierno en la actividad regulatoria (tesis de la regulación mínima), y por otra a los efectos negativos que tienen los intereses privados y capitalistas en la actividad regulatoria (tesis de la regulación máxima). Sostendremos que ambas tesis apuntan a estrategias de investigación poco promisorias ya que hacen énfasis en quién regula, y no en cómo se regula, lo cual resulta contradictorio con el carácter finalista de la regulación en nuestra Constitución. Por esta razón propondremos la necesidad de hacer énfasis en la forma como se regula. De este modo, plantearemos los puntos centrales de las tesis de la 
juridificación y del trilema regulatorio, en tanto alternativas teóricas para explicar la "crisis regulatoria" en materia de servicios públicos domiciliarios. Por último, y a manera de conclusión propositiva, sostendremos por qué razones esta agenda de investigación podría resultar factible y promisoria en el estudio de la regulación de servicios públicos domiciliarios.

\section{La regulación dentro del diseño constitucional}

En la Constitución colombiana de 1991 se previó un modelo de “(...)

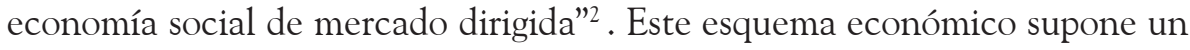
complejo equilibrio entre la libertad de mercado y la intervención del Estado con miras a la consecución del interés social. Esto ya que aunque la Constitución considera la libertad de la actividad económica y la iniciativa privada como ejes de nuestro sistema económico (art. 332), establece en el artículo 333 que "(...) la dirección general de la economía estará a cargo del Estado". Al mismo tiempo, tal direccionamiento del Estado, al haberse constituido un modelo Social de Derecho, debe orientarse a la redistribución justa de los recursos. Como lo afirma la Corte Constitucional, en nuestra Constitución "(...) el papel del mercado como instrumento de asignación de recursos se concilia con el papel económico, político y social del Estado redistribuidor de recursos..." ${ }^{3}$.

Podría afirmarse que el Constituyente de 1991 buscó la construcción de un modelo de sociedad en el cual "la mano invisible del mercado y el brazo visible del Estado" 4 trabajasen como un único órgano. Nuestro diseño Constitucional habría buscado, pues, un punto intermedio entre el maximalismo del Estado de Bienestar y el minimalismo del estado libertario. Pero si la "Constitución Económica" no se ha decidido ni por un sistema asistencialista ni por un Estado "gendarme", ihacia qué punto de este amplio espectro tiende entonces nuestra Constitución Económica? La respuesta parece encontrarse en el modelo del Estado Regulador.

La Corte Constitucional ha afirmado que el Constituyente de 1991 concibió la regulación como la forma idónea de intervención estatal en la economía, lo cual está reflejado a lo largo del Capítulo 5 del Título XII de la

\footnotetext{
${ }^{2}$ Corte Constitucional. Sentencia T-251 de 1993, (M.P. Eduardo Cifuentes Muñoz).

${ }^{3}$ Corte Constitucional. Sentencia C-265 de 1994, (M.P. Eduardo Cifuentes Muñoz).

${ }^{4}$ Spulber, D. F. (1989). Regulation and Markets. Cambridge, The MIT Press., p. 3

${ }^{5}$ Corte Constitucional. Sentencia C-150 de 2003, (M.P. Manuel José Cepeda).
} 
Constitución, dedicado al "Régimen Económico y de Hacienda Pública" 5. Esta forma de intervención estatal tiene preeminencia en nuestra Constitución sobre el sistema de redistribución directa del ingreso y de la propiedad con objeto de alcanzar un "orden político, económico y social justo" como sobre la función de estabilización de la economía (artículos 334, 339, 347, 371 y 373 de la C.P.). De esta manera, el Estado colombiano no centra su labor de intervención económica en la asignación directa de recursos, pero tampoco se limita únicamente a garantizar la propiedad privada y el cumplimiento de los contratos entre individuos. La intervención del Estado en la economía se centra, más bien, en la regulación económica y social de diversos sectores y actividades dentro de los parámetros fijados en la Constitución. Aunque no adjudica directamente bienes y servicios, sí controla indirectamente tal asignación a través de la expedición de normas y la implementación de medidas regulatorias ${ }^{7}$.

La regulación del Estado se materializa en un amplio conjunto de medidas específicas destinadas ya sea a intervenir en las acciones de mercado, o a alterar de una forma determinada las decisiones de oferta y demanda. La tarea regulatoria del Estado parte del supuesto de que existen fallas de mercado. Esto significa que los mecanismos de mercado no siempre pueden realizar una asignación óptima de bienes y servicios ${ }^{8}$, por lo que en tales casos se hace necesaria la intervención del Estado ${ }^{9}$. En un sentido general, el Código Civil puede entenderse como una modalidad de regulación estatal de la economía, debido a que garantiza la actividad económica privada dentro de los parámetros del derecho y fija al mismo tiempo los patrones básicos de las relaciones de mercado en una sociedad ${ }^{10}$. En un sentido particular la regulación estatal sobre servicios públicos domiciliarios -la cual propondremos como ejemplo en este ensayo- es un caso concreto de regulación estatal en un sector de la economía.

\footnotetext{
${ }^{6}$ Constitución Política de Colombia, Preámbulo.

${ }^{7}$ Garcia, C. A. and L. Villegas (2001). Regulación de los Servicios Públicos: Redefinición

Constitucional del Estado Colombiano. Derecho Constitucional-Perspectivas Críticas. Bogotá, Observatorio de Jusiticia Constitucional Uniandes-Editorial Legis.

${ }^{8}$ Las asignaciones óptimas de mercado se definen según el criterio de Pareto como aquellas situaciones en las cuales la posición de ningún consumidor puede mejorarse sin que resulte empeorada la situación de otro consumidor. Spulber, D. F. (1989). Regulation and Markets. Cambridge, The MIT Press., p. 3.

${ }^{9}$ Ibid.

${ }^{10}$ Corte Constitucional. Sentencia C-150 de 2003, (M.P. Manuel José Cepeda).
} 


\section{Las paradojas del Estado de Bienestar}

Resulta razonable pensar que al adoptar el modelo de Estado Regulador nos estamos quedando con lo mejor de los modelos del Estado de Bienestar y del Estado Mínimo, al mismo tiempo que evitamos las paradojas de ambos. Los ataques que corrientemente se hacen a estos esquemas económicos son variados y contundentes. Es interesante constatar, por ejemplo, que el Estado de Bienestar contemporáneo ha encontrado fuertes críticas y objeciones no sólo desde la derecha liberal, sino también desde la izquierda socialista ${ }^{11}$.

Tras la Segunda Guerra Mundial el Estado de Bienestar ha operado como la fórmula de paz de las sociedades capitalistas industrializadas en la medida en que ayudó significativamente a mitigar los conflictos de clase, reducir las relaciones asimétricas entre trabajo y capital, así como trasladar la asistencia estatal a un vasto número de personas que se encuentran en situaciones especiales de riesgo y necesidad ${ }^{12}$. Pero pese a los indiscutibles logros de este modelo, desde mediados de los años setenta éste ha sido objeto de agudos cuestionamientos no sólo en su aplicación sino en sus propios presupuestos teóricos. El Estado de Bienestar pasó de ser la cura keynesiana para la caída en depresiones económicas, a ser la enfermedad que ataca la estabilidad económica y política. Partiendo de este supuesto las doctrinas económicas neo-liberales que surgieron de la profunda recesión económica de los setenta, señalan al aparato de bienestar como un desincentivo a la inversión en tanto impone unos gravámenes y regulaciones insostenibles sobre el capital, y como un desincentivo al trabajo debido a que otorga concesiones y titulaciones a grupos sociales particulares (tales como los sindicatos y los desempleados), que resultan incompatibles con las condiciones de libertad y autonomía propias de los mecanismos de mercado ${ }^{13}$.

Por su parte las críticas de la izquierda han buscado poner al descubierto que el Estado de Bienestar no es sólo ineficiente, sino represivo y engañoso en tanto alternativa para la emancipación social. Ineficiente ya que se orienta a compensar los efectos negativos de las fallas del mercado capitalista a través de la prestación de una gran variedad de bienes y servicios, y no las causas de las contingencias y necesidades individuales que el Estado de

\footnotetext{
${ }^{11}$ Offe, C. (1985). Contradictions of the Welfare State. Cambridge, The MIT Press.,pp. 147-161.

${ }^{12}$ Ibid., p. 149.

${ }^{13}$ Ibid, p. 149.
} 
Bienestar busca atenuar ex post facto. En este sentido el Estado de Bienestar actúa "cuando ya es demasiado tarde" 14 . Según estas críticas, el Estado de Bienestar es también represivo ya que para alcanzar sus objetivos genera un sistema de control social que vulnera la autonomía del "cliente", esto es, del ciudadano. Teorías como las de Habermas, Apel y Reich muestran una preocupación constante por los efectos nocivos que tiene el Estado de Bienestar sobre la libertad y autonomía humanas. De las obras de estos autores se desprende la posición según la cual hay espacios sociales en los cuales es recomendable que no intervengan los mecanismos de bienestar del Estado, en tanto esto puede generar agudas disfunciones en la forma como los individuos entienden su papel en la sociedad ${ }^{15}$.

Este tipo de teorías parten de la consigna "Mehr Freiheit, weniger Staat" (más libertad, menos Estado), la cual era común a las posiciones críticas frente al Estado de Bienestar que empezaron a ocupar un terreno propio en la sociología jurídica alemana a comienzos de los años $70^{16}$. Aunque estas teorías compartían preocupaciones generales con las tesis neoliberales y libertarias en cuanto a la limitación del campo de acción individual que implicaba la intervención del Estado de Bienestar, se separaban radicalmente de éstas en tanto no proponían ni una reducción drástica de las funciones del Estado ni una primacía de los mecanismos de mercado. El presupuesto del que parten estas tesis es que bajo el esquema del Estado de Bienestar el sistema jurídico y el administrativo han extendido sus redes, con devastadoras consecuencias en algunos casos, a áreas de la vida humana que antes no estaban cubiertas: la enfermedad, la infancia, el número de hijos, los costos de vivienda, la vejez, la invalidez, las enfermedades físicas o mentales, entre muchas otras. ${ }^{17}$. Las implicaciones que tiene este fenómeno en términos de las posibles limitaciones a la libertad humana son bastante serias. Pasar, por ejemplo, de las dos provisiones referentes al empleo incluidas en el Código Civil Napoleónico a la profusa regulación legal sobre el trabajo que contienen jurisdicciones como la francesa o la alemana implica, según Simitis, que se pasa del esquema del ciudadano al del empleado ${ }^{18}$. El individuo en este

\footnotetext{
${ }^{14}$ Ibid, p. 154.

${ }^{15}$ Holtschneider, R. (1991). Normenflut und Rechtsversagen. Baden-Baden, Nomos Recht., p. 30.

${ }^{16}$ Kohler, G. (1987). Verrechtlichung und Verantwortung, Themen einer Epochenschwelle.

Verrechtlichung und Verantwortung. Stuttgart, Haupt. pp. 7-15

${ }^{17}$ Zacher, H. F. (1987). Juridification in the Field of Social Law. Juridification of the Social Spheres.

Berlín, Walter de Gruyter., pp.374-411.

${ }^{18}$ Simitis, S. Ibid.Juridification and Labor Relations., pp.113-153.
} 
caso ya no se siente parte de una sociedad en la que puede ejercitar sus libertades políticas, sino perteneciente a una agencia estatal, a una empresa o a una corporación privada. Otro ejemplo lo encontramos en el impacto que tiene la regulación jurídica del desempleo sobre los individuos que recurren a la asistencia estatal, lo cual implica en muchos casos la comprensión distorsionada que tienen estos individuos de sí mismos como seres pasivos y necesitados de auxilio, especie de minusválidos sociales ${ }^{19}$.

Pero tal vez sea la obra de Jürgen Habermas la que ha mostrado con mayor consistencia cómo el derecho se ha constituido en un medio de intervención social dentro el proyecto del Estado de Bienestar, lo cual según este autor ha traído consecuencias desastrosas ${ }^{20}$. Debido a sus estrechas conexiones con el poder y el dinero, el derecho como medio ha sido tecnificado y desmoralizado en el Estado de Bienestar, por lo que sus logros sólo pueden evaluarse a la luz de su éxito instrumental y no con base en criterios éticos ${ }^{21}$. El diagnóstico de Habermas sobre el intervencionismo del Estado de Bienestar hace énfasis en el efecto disgregador que tiene el derecho como medio interventor y regulador en las áreas sociales estructuradas comunicativamente y organizadas informalmente ${ }^{22}$. Para Habermas, en el esquema de Estado de Bienestar se genera una nociva competencia entre el Estado y los individuos sujetos a su intervención. Esta competencia, según Habermas, es de "suma cero", ya que lo que gana el Estado en capacidades de regulación lo pierden los individuos en autonomía, y viceversa ${ }^{23}$. Mientras en el modelo de Estado liberal los sujetos del derecho privado estaban limitados en sus actuaciones únicamente por las contingencias de su situación social, en el Estado de Bienestar los individuos se enfrentan a las provisiones paternalistas de una voluntad política superior que interviene en las contingencias sociales, y que además regula los procesos sociales con objeto de brindar las condicio-

\footnotetext{
${ }^{19}$ Las propuestas de ingresos o asignaciones universales pretenden desmontar la "trampa" del desempleo, y evitar que un sector de la población (el de los desempleados) siga siendo considerado como un grupo de parias o "intocables". Véase las propuestas de un ingreso mínimo universal de Van Parijs, P. (1995). Real Freedom for All. What (if anything) Can Justify Capitalism?, Oxford University Press. Aunque con implicaciones distintas, las propuestas de Ackerman y Alstott se orientan a una asignación universal de capital. Véase Ackerman, B. and A. Alstott (1999). The Stakeholder Society. New Haven, Yale University Press.

${ }^{20}$ Baxter, H. (2002). "System and Lifeworld in Habermas's Theory of Law." Cardozo Law Review 23 Cardozo L. Rev. 473.

${ }^{21}$ Ibid.

${ }^{22}$ Ibid.

${ }^{23}$ Habermas, J. (1996). "Paradigms of Law." Ibid. 17 Cardozo L. Rev. 771.
} 
nes necesarias para un ejercicio igualitario de las libertades individuales ${ }^{24}$. Con este loable objetivo, el aparato bienestarista provee servicios y facilita oportunidades vitales al garantizar patrones de seguridad social, atención médica, vivienda, ingreso mínimo, educación, esparcimiento, etc. Sin embargo la paradoja surge cuando el Estado de Bienestar, agobiado por las innumerables tareas que implica brindar las bases materiales para el ejercicio de una existencia humana digna, tiende inevitablemente a imponer patrones "normales" de comportamiento sobre sus clientes ${ }^{25}$. Para Habermas este proceso de normalización burocrática del mundo de la vida implica una limitación significativa de la autonomía individual, lo cual es precisamente aquello que pretende garantizar el Estado de Bienestar al proveer las condiciones materiales para el ejercicio de las libertades individuales ${ }^{26}$. El fenómeno de la juridificación surge en este contexto no sólo como una densificación de una red ya existente de regulaciones jurídicas, sino como una superimposición que hace el sistema jurídico sobre un contexto de acción comunicativa antes no regulado, en el cual el derecho actúa no como una institución sino como un medio ${ }^{27}$. Esta intervención del derecho como medio en contextos informales del mundo de la vida genera, según Habermas, agudas disfunciones sociales que pueden detectarse en fenómenos como la pérdida de sentido y de motivaciones, las perturbaciones en la identidad colectiva, la anomia, la alienación y las psicopatologías ${ }^{28}$.

Por último, el Estado de Bienestar representa una falsa concepción de la emancipación social ya que ha sido usado por las élites dominantes como una cortina de humo en su propósito de desmantelar la lucha de clases. Este conjunto de críticas recoge tesis como las de Otto Kirchheimer, quien desde la doctrina marxista se propuso mostrar cómo a través del derecho laboral la élite política dominante había logrado formalizar y legalizar los conflictos laborales con el objetivo de debilitar el movimiento obrero, así como desmontar las bases de la lucha de clase ${ }^{29}$. La tendencia que tempranamente detectó Kirchheimer ${ }^{30}$ y alrededor de la cual girará más adelante buena

\footnotetext{
${ }^{24}$ Ibid.

${ }^{25}$ Ibid.

${ }^{26}$ Ibid.

${ }^{27}$ Habermas, J. (1987). Law as Medium and Law as Institution. Juridification of the Social Spheres. Berlín, Walter de Gruyter.,

${ }^{28}$ Habermas, J. (1988). Teoría de la Acción Comunicativa. Madrid, Taurus., Cap. VIII.

${ }^{29}$ Teubner, G. (1990). Verrechtlichung - ein ultrazyklisches Geschehen. Frankfurt, Humboldt.

${ }^{30}$ Véase, Kirchheimer, O. (1961). Political Justice, Princeton University Press.
} 
parte de las críticas al Estado de Bienestar, consistía en una politización del derecho y en una juridificación de la sociedad ${ }^{31}$. Para Kirchheimer esta tendencia no surgió espontáneamente, sino que había sido creada de manera estratégica por las élites en el poder para petrificar los movimientos sociales a través de una colonización, por parte del derecho, de áreas de la sociedad que anteriormente no se encontraban reguladas por el Estado. A principios de la década de los 70 la repercusión de esta tesis de Kirchheimer sirvió como fundamento para el surgimiento de la discusión alrededor de la utilización estratégica del Estado de Bienestar. La influencia de la obra de Kirchheimer se pudo observar, por ejemplo, en el debate sobre la domesticación y debilitamiento del movimiento obrero a través de la regulación jurídica de los sindicatos propia del Estado de Bienestar ${ }^{32}$.

Una posición común a estas tesis críticas es la de señalar la falsa ideología que se esconde tras el adoctrinamiento del Estado de Bienestar, el cual supone una cooperación entre clases sociales, una anulación de las luchas económicas y políticas, así como una confianza irrestricta en la seguridad social y en el crecimiento económico ${ }^{33}$. Según estas posiciones tal desaparición ficticia del conflicto social, operada a través del entramado del Estado de Bienestar, es precisamente el arma más eficaz que ha diseñado la élite en el poder para desarticular la lucha de clases.

\section{El minimalismo estatal}

La identificación de las paradojas que genera el Estado de Bienestar llevó a que a partir de mediados de los años 70 se clamara, desde influyentes sectores de la academia y de las políticas públicas, por una "retirada" del Estado de la economía ${ }^{34}$. Las teorías neoliberales creían haber identificado con claridad las "fallas del Estado" y los costos sociales que implicaba la

\footnotetext{
${ }^{31}$ Aunque teórica e ideológicamente opuesta, la tesis de Kirchheimer es contemporánea a la visión crítica de Carl Schmitt sobre la "socialización del Estado" (1926). Ernst Horsthoff (1971) recoge elementos de la obra de Kirchheimer para proponer su tesis de la "judicialización de la sociedad. Véase, Voigt, R. (1983). Verrechtlichung und Entrechtlichung im Kontext der Diskussion um den Wohlfartsstaat. Gegentendenzen zur Verrechtlichung. W. Verlag. Opladen. ${ }^{32}$ Simitis, S. (1987). Juridification and Labor Relations. Juridification of the Social Spheres. Berlín, Walter de Gruyter.,pp. 113-151.

${ }^{33}$ Offe, C. (1985). Contradictions of the Welfare State. Cambridge, The MIT Press., pp. 154-157.

${ }^{34}$ Bruton, H. J. (1992). International Aspects of the Role of Government in Economic Development. State and Market in Development. London, Lynne Rienner,p. 109
} 
intervención de éste en la economía. Por esta vía las teorías neoliberales y monetaristas condenaban como absurda la posibilidad de un Estado redistribuidor de la riqueza, especialmente en las economías pobres y deficitarias del tercer mundo. De esta manera, a finales de los 80 se implementó en un número importante de países subdesarrollados (entre ellos Colombia) un proceso de reformas orientadas a la privatización y a la reducción del aparato estatal, con lo cual se pretendía emular la experiencia de países como Inglaterra y Estados Unidos ${ }^{35}$.

Con radicalidad similar a la de teorías como las de A.C. Pigou, según las cuales el Estado era incapaz de hacer daño en su funcionamiento ${ }^{36}$, la economía política neoclásica asociada con la escuela de Chicago y con las teorías de Public Choice, defendía la idea de que por definición los mecanismos de mercado no podían traer consecuencias negativas ${ }^{37}$. Obviamente, esto bajo el supuesto de que no fueran intervenidos o regulados desde el sector público. Según estas posiciones, la intervención del Estado en los mercados libres no puede traer consecuencias positivas en la medida en que los individuos que operan el aparato estatal -políticos y burócratas - utilizan su dominio sobre determinadas áreas del mercado para obtener beneficios personales (rent seeking), lo que conduce inexorablemente a una asignación ineficiente y desigual de recursos, empobrecimiento general y reducción de libertades individuales ${ }^{38}$. Es debido a estos fenómenos que, según la mayoría de estas tesis, en la guerra del Estado contra la pobreza es la última la que siempre triunf $\mathrm{a}^{39}$. Las recomendaciones que en consecuencia se hacen (y de las cuales dependen muchas veces préstamos de bancos y organismos inter-

\footnotetext{
${ }^{35}$ Biersteker, T. Ibid.The Logic and Unfulfilled Promise of Privatization in Developing Countries, Lynne Riener., 195-216.

${ }^{36}$ La mayor contribución de Pigou a la ciencia económica fue la creación de la economía "welfarista" como rama de la economía. Para Pigou las fallas del mercado hacían obvia la necesidad de medidas correctivas por parte del Estado. De acuerdo con Pigou, cuando los productos marginales privados y sociales coinciden, y no se presentan monopolios, la asignación de recursos será eficiente y la mano invisible puede operar sin cortapisas. En la realidad, los productos netos privados y sociales difieren normalmente, y se presentan diversos tipos de fallas de mercado (congestión, polución, agotamiento de recursos, información). De esta manera, para Pigou la intervención del Estado en la economía se hace inevitable Niehans, J. (1990). A History of Economic Theory. Baltimore, The Johns Hopkins University Press. PP. 318-323. ${ }^{37}$ Streeten, P. P. (1992). Against Minimalism. State and Market Development. London, Lynne Rienner Publishers., p. 25.

${ }^{38}$ Ibid., p. 24.

${ }^{39}$ Ibid., p. 17.
} 
nacionales a países del tercer mundo) tienden hacia una liberalización, privatización, descentralización y desregulación de la economía, a través de las cuales se impida que los "evidentes pies del Estado pisoteen las manos invisibles del mercado" 40 .

\section{La necesidad de la regulación}

Sin embargo, al haber adoptado nuestro constituyente el modelo económico de la regulación partió implícitamente del supuesto de que las manos invisibles del mercado, dejadas a su libre arbitrio, pueden conducir a resultados injustos e ineficientes ${ }^{41}$. Cuando nos decidimos por la regulación estamos partiendo del supuesto de que el funcionamiento de los mecanismos de mercado conduce en ciertos casos a fallas y paradojas que sólo pueden resolverse con la intervención estatal.

Como bien se sabe la regulación estatal se orienta a frenar o anular la tendencia hacia la conformación de monopolios que presentan los merca$\operatorname{dos}^{42}$. Contrariamente a lo afirmado por las nuevas teorías del laissez faire, la regulación pública que intenta bloquear los monopolios, en lugar de ser un obstáculo y una disuasión a la libre competencia, es en realidad la medida necesaria para asegurar el buen funcionamiento de los mercados.

Pero la importancia de la regulación estatal no sólo se define respecto a la contención de los monopolios. Otro conjunto de fallas de mercado que la regulación estatal busca resolver es el relacionado con los problemas de ac-

${ }^{40}$ Ibid., p. 25. En la edición del 19 de julio de 2004 del Periódico Financial Times, el Ministro de Hacienda de Colombia afirmó que el Gobierno colombiano se prepara a adelantar el que tal vez sea el proceso de privatización más ambicioso de América Latina. Siguiendo las pautas del acuerdo establecido entre Colombia y el FMI, según el cual el país se compromete a limitar su déficit fiscal en una cifra inferior al 2.5 por ciento del PIB, en los próximos años el gobierno se apresta a privatizar un gran número de entidades estatales, ofreciendo al sector privado alrededor de 10 billones de dólares en acciones de tales entidades.Véase: http://search.ft.com/ search/article.html?id $=040719000762$ Eqquery $=$ CarrasquillaEsusc_appId $=$ totalSearchEstate $=$ Form ${ }^{41}$ Los procesos de privatización adelantados en Rusia durante la década de los noventa, en los cuales gran parte de los recursos estatales -incluyendo los bancos- pasaron a manos de la mafia , se han convertido en un caso paradigmático de lo que puede ocurrir con la implementación radical de políticas libertarias y de Estado Mínimo. Véase Parker, C. and J. Braithwaite (2003). Regulation. The Oxford Handbook of Legal Studies. Oxford, Oxford University Press., p. 124. ${ }^{42}$ Sunstein, C. (1990). After the Rights Revolution-Reconceiving the Regulatory State. Cambridge, Harvard University Press., p. 48. 
ción colectiva, coordinación y costos de transacción generados por el funcionamiento del mercado ${ }^{43}$. El caso de la polución es un buen ejemplo de las funciones que el mercado no puede cumplir, y que la regulación busca suplir. Los costos de polucionar están tan difundidos a lo largo de la sociedad y son tan bajos a nivel individual, que las personas no encontrarían en los mecanismos de mercado un incentivo lo suficientemente fuerte para no polucionar. Cada polucionador se involucraría de esta manera en una conducta racional que tendría como resultado un empeoramiento de las condiciones sociales agregadas. Pese a que las personas obren racionalmente al polucionar "un poco", el nivel agregado de polución podría estar muy por debajo del óptimo social. Para alcanzar tal nivel óptimo, por lo tanto, se hace necesaria la regulación del Estado, a través de la cual se aseguraría la acción colectiva que el mercado no puede garantizar ${ }^{44}$. En ocasiones el mercado impone costos muy altos a la acción colectiva, y ante la ausencia de fuertes normas sociales que aseguren la cooperación, se hace indispensable la intervención estatal de modo que se supla la dificultad y el costo que conllevaría buscar acuerdos de cooperación entre individuos.

No obstante, desde su visión particular del Análisis Económico del Derecho Richard Posner ha sostenido que, en casos como el de la polución, la regulación estatal es innecesaria si se cuenta con un sistema judicial capaz de resolver efectivamente los daños generados por la contaminación ambiental ${ }^{45}$. Según Posner, problemas como los monopolios y los de acción colectiva no son fallas de los mecanismos de auto-regulación del mercado, sino deficiencias del mercado incentivadas por normas jurídicas ineficientes ${ }^{46}$. Para Posner, la opción que se nos plantea no es entre la regulación estatal y el mercado, sino entre los mecanismos judiciales y la regulación estatal directa. De acuerdo con este autor, para combatir fenómenos sociales como el de la polución es preferible utilizar los mecanismos judiciales que los de regulación directa, debido a que el método judicial no depende tanto de los funcionarios públicos (jueces), sino de los ciudadanos, las víctimas y los abogados, lo que reduce el peligro de la búsqueda de renta (rent seeking) por razones de auto-interés político, que es según Posner lo que hace de la regulación directa una herramienta tan poco eficiente y $\tan \operatorname{costos}^{47}$. Por otra

\footnotetext{
${ }^{43}$ Ibid., p. 49.

${ }^{44}$ Ibid., p. 50.

${ }^{45}$ Posner, R. (1992). Economic Analysis of Law. Boston, Little, Brown and Company., p. 368.

${ }^{46}$ Ibid., p. 367.

${ }^{47}$ Ibid., p. 369.
} 
parte, Posner argumenta que la regulación, al estar basada en una lógica de la prevención y no de la compensación, la hace mucho más costosa debido a que debe ser continua, lo que la diferencia radicalmente de la solución judicial, la cual sólo es invocada cuando alguien argumenta haber recibido un perjuicio ${ }^{48}$. En este sentido, según Posner la regulación directa debe reemplazar a la intervención judicial excepcionalmente, y únicamente en áreas en las que el derecho no pueda proveer incentivos suficientes para una conducta eficiente debido a que los perjuicios infligidos a la víctima son o demasiado pequeños o demasiado grandes ${ }^{49}$.

Aunque Posner pareciera presentar estos casos como una excepción, lo cierto es que los mismos mecanismos de mercado impondrían unos costos tan altos y unos beneficios tan bajos a la búsqueda de una indemnización, que cada sujeto afectado buscaría racionalmente, antes de demandar, vincularse como free-rider en la demanda de otro individuo ${ }^{50}$. El resultado de esta situación es el de un gran número de free-riders que nunca demandarían, por lo que en el caso de la polución llegaríamos a un resultado muy por debajo del óptimo social. Si seguimos la recomendación de Posner en esta materia, podríamos llegar a una situación de alta polución en la que ni el contaminador ni los afectados tendrían incentivos suficientes para disminuir los niveles de contaminación. Sin una regulación estatal efectiva en casos como el de la polución, tendríamos según Cass Sunstein un gran número de individuos involucrado en un "dilema del prisionero", en el cual un comportamiento individual absolutamente racional conduciría a una situación mucho peor para los individuos que la que podrían alcanzar si actuaran cooperativamente $^{51}$. Para resolver esta paradoja generada por los mecanismos de mercado se hace indispensable la regulación estatal. Como lo sostiene Sunstein, en estos casos la regulación, lejos de ser una especie de paternalismo rampante, debe ser entendida como un esfuerzo orientado a la satisfacción de los intereses privados ${ }^{52}$.

Por otra parte, los mecanismos de mercado generan información inadecuada en áreas que, de no ser por la regulación estatal, producirían graves

\footnotetext{
${ }^{48}$ Ibid., p. 369.

${ }^{49}$ Ibid., p. 368.

${ }^{50}$ Sunstein, C. (1990). After the Rights Revolution-Reconceiving the Regulatory State. Cambridge,

Harvard University Press., p. 49.

${ }^{51}$ Ibid., p. 49.

${ }^{52}$ Ibid., p. 52.
} 
perjuicios a los clientes de una gran variedad de bienes y servicios. El mercado revela información deficiente o nula ya que la producción y el procesamiento de ésta tiene un costo generalmente alto que el sector privado no siempre está dispuesto a asumir. La función de la regulación estatal no es sólo asegurar la autonomía al permitir la satisfacción de preferencias, sino la promoción de la autonomía en el proceso de formación de preferencias ${ }^{53}$. La satisfacción de las preferencias inmediatas es una concepción incipiente de la libertad y la autonomía; sin embargo, es el único tipo de satisfacciones que puede aportar el mercado. Una noción más sólida de autonomía individual debe garantizar que las personas decidan con información suficiente y sin constreñimientos ilegítimos en la formación de preferencias. Así, un trabajador fabril no conoce de antemano hasta qué punto el material con el que labora puede resultar cancerígeno. Si no contáramos con regulación estatal la empresa podría producir un nivel informativo que pudiese resultar eficiente en términos económicos, aunque en términos de salud y seguridad social estuviese muy por debajo del punto que actualmente consideramos óptimo. Piénsese también en la producción de productos peligrosos, frente a los cuales existen pocos incentivos económicos para proveer información completa y detallada sobre las condiciones de inseguridad que genera su uso o consumo. Si no existiera una regulación unificada en torno a este tipo de producción, los mecanismos de mercado conducirían a que las empresas que detallan cuidadosamente la posible inseguridad de sus productos (como los medicamentos o los productos de alto voltaje) se vieran ubicadas en una posición desventajosa frente a las que no lo hacen ${ }^{54}$. Según Sunstein, si no contáramos con regulaciones sobre riegos y seguridad, esta asimetría de información tarde o temprano sacaría del mercado a los productos de las empresas que detallan su potencial peligro (y que por lo tanto son más seguros), ya que (1) los productos más seguros no se venderían por un precio mayor que los menos seguros, (2) los productos más seguros serían más costosos de producir, (3) los consumidores no estarían en capacidad de discernir la diferencia ${ }^{55}$. Es este tipo de disfunciones y fallas de mercado las que la regulación estatal se propone mitigar.

Una paradoja adicional generada por los mercados es el de las externalidades. Sabemos que los mercados arrojan externalidades, las cuales nunca serían asumidas por los responsables de éstas si no existiera la

\footnotetext{
${ }^{53}$ Ibid., p. 40.

${ }^{54}$ Ibid., p. 52.

${ }^{55}$ Ibid., p. 52.
} 
regulación estatal. Por externalidad se puede entender todo tipo de costos que tienen las conductas privadas, los cuales no son retribuidos por los mercados $^{56}$. Producir medicamentos peligrosos o artículos que impliquen un menoscabo al medioambiente genera una amplia gama de costos que no son internalizados por el productor, sino que se dispersan en el conjunto de la sociedad -por ejemplo entre las personas que conviven en las inmediaciones de una fábrica que utiliza "energía sucia", entre los participantes en el mercado de seguros, entre los contribuyentes, etc. La regulación en este caso se hace indispensable para reducir el impacto social negativo que tiene el funcionamiento del mercado.

Sin embargo, no es sólo debido a fallas del mercado que se hace necesaria la regulación estatal. Ante los resultados moral y políticamente arbitrarios que el mercado puede producir, resulta indispensable la intervención pública a través de la regulación. Sabemos que las decisiones que los individuos toman a nivel político difieren en muchos casos de sus predilecciones en el mercado ${ }^{57}$. Los compromisos que se establecen a través de criterios democráticos pueden ir en contra del curso de acción que elegiría tomar un actor racional dentro del mercado. Así, muchas personas preferirían votar por una televisión diversa y de alta calidad, pese a que como consumidores prefieran telenovelas como Pasión de Gavilanes. El mercado, dejado por su cuenta, satisface unas preferencias inmediatas que muchas veces van en contra de proyectos sociales establecidos a través del proceso democrático. Por ejemplo, de no existir una regulación laboral, existiría un mercado abierto para las personas que desean trabajar sin límite de tiempo, sin seguridades básicas en el lugar de trabajo, sin prestaciones sociales, o por una remuneración inferior al salario mínimo; del mismo modo, si no existiera regulación sobre radio y televisión cultural, las personas que buscan opciones musicales distintas a Britney Spears se encontrarían con una oferta radial y televisiva mucho más homogeneizada por las predilecciones de un mercado masivo. Mientras el mercado busca satisfacer las preferencias de los usuarios aquí y ahora (sin importar qué tipo de preferencias sean), la regulación estatal en muchos casos busca satisfacer aspiraciones públicas (tales como tener condiciones laborales más justas o una televisión más diversa) a través del fomento de "preferencias sobre preferencias" 58 . Las "preferencias sobre preferencias" incentivadas por la regulación no buscan satisfacer necesariamente los intereses de unos consumidores actuales, sino que por ejemplo buscan inter-

\footnotetext{
${ }^{56}$ Ibid., p. 55.

${ }^{57}$ Ibid., p. 57.

${ }^{58}$ Ibid., p. 42.
} 
venir o modificar cursos de acción que, pese a resultar satisfactorios para un gran número de ciudadanos "aquí y ahora", pueden resultar nocivos para generaciones futuras. Tal es el caso del manejo de los recursos no renovables o de los fondos pensionales, los cuales van muchas veces en contra de las preferencias de consumidores actuales debido a que están destinados a proteger los intereses de futuros consumidores, o a los mismos consumidores actuales a la vuelta de un número determinado de años. Por otra parte, los mecanismos de mercado no sólo tienen dificultades en considerar "preferencias sobre preferencias", sino las preferencias "reales" de los consumidores. Esto ya que el mercado sólo puede satisfacer las preferencias endógenas a actos de consumo o a prácticas existentes. La paradoja de las preferencias endógenas surge, por ejemplo, en el caso del consumo de sustancias adictivas. Debido a que los mecanismos de mercado pueden satisfacer las preferencias de un adicto a la heroína (la cual es una preferencia endógena al acto de consumo), la regulación estatal sobre narcóticos se encarga de desincentivar el surgimiento de la preferencia inicial por el consumo, en la medida en que la preferencia "real" del posible consumidor sería, en primer lugar, la de no convertirse en un adicto a la heroína.

Pero tal vez sea la posibilidad de que los mecanismos de mercado discriminen a ciertos grupos poblacionales lo que haga más urgente y necesaria la intervención estatal a través de la regulación. Los mercados, se afirma con cierta frecuencia, desincentivan la discriminación de minorías o de grupos poblacionales subordinados. Se podría argumentar, en efecto, que una empresa discriminadora se encuentra en una posición desventajosa en el mercado frente a las empresas que no discriminan, debido a que las últimas tienen mayores posibilidades de encontrar mano de obra calificada ya que cuentan con un mayor rango de selección poblacional. Lo mismo se puede decir de la empresa que discrimina entre grupos poblacionales para establecer transacciones comerciales, la cual se encontrará en desventaja frente a la que no la hace y que tiene en consecuencia mayores posibilidades de demanda. Sin embargo, las presiones del mercado no son suficientes para frenar la discriminación ${ }^{59}$. Sunstein muestra que las decisiones de terceras partes pueden conducir a los empleadores, por ejemplo, por el camino de la discriminación ${ }^{60}$. Piénsese en los clientes de una tienda de artículos de lujo que prefieren no tratar con personas de raza negra, en los de una aerolínea

\footnotetext{
${ }^{59}$ Ibid., p. 61.

${ }^{60}$ Sunstein, C. (1997). Free Markets and Social Justice. New York, Oxford University Press., p. 153.
} 
que prefieren no tener pilotos mujer, o en los de un bar que prefieren tener al lado personas vestidas de una manera determinada; en todos estos casos las terceras partes -los clientes- pueden presionar indirectamente al empleador para que discrimine al momento de darle el trabajo a alguien o de iniciar una transacción comercial. En todos estos casos se hace indispensable la regulación del Estado en tales decisiones económicas con objeto de evitar la discriminación. Los mecanismos de mercado no sólo resultan insuficientes para evitar la discriminación; en ocasiones son precisamente estos los que la fomentan. Debido a esto, los sujetos del mercado requieren de regulación estatal para evitar ser discriminados y para que no se les lleve a discriminar. Precisamente esta última fue la situación que rodeo en los Estados Unidos la expedición del Civil Rights Act de $1964^{61}$. En esta coyuntura muchos restaurantes y hoteles que en el pasado habían discriminado a los negros buscaron la protección de la regulación estatal. De no haberse contado con una estricta regulación unificada contra la discriminación, los restaurantes que decidieron no discriminar por su propia cuenta habrían cedido importante terreno comercial frente a los restaurantes que sí satisfacían las preferencias discriminatorias de muchos de sus clientes.

\section{Un ejemplo: la regulación de los servicios públicos domiciliarios en Colombia}

La confianza irrestricta en los mecanismos de mercado o la constitución de un Estado redistribuidor y reparador, son los dos extremos entre los que se mueve la regulación estatal. Hemos visto, por una parte, que la regulación estatal surge como una respuesta a las fallas del mercado, no sólo en lo relativo a los problemas de externalidades, coordinación e información, sino en lo relacionado con las contradicciones éticas de los mercados, así como con sus efectos nocivos sobre los derechos de ciertos grupos sociales. Pero por otra parte el esquema de regulación busca evitar las paradojas del Estado de Bienestar, en la medida en que su forma de intervenir en la economía no vulnera la autonomía individual ni burocratiza perniciosamente áreas del "mundo de la vida" que se deberían mantener alejados del "brazo visible" del Estado.

Una de las hipótesis de las cuales hemos partido en este ensayo es que bajo el esquema de la Constitución colombiana de 1991, la regulación de los servicios públicos domiciliarios puede entenderse como un ejemplo de inter-

${ }^{61}$ Ibid., p. 154. 
vención estatal que busca eludir las paradojas del Estado de Bienestar y del Estado Mínimo, así como maximizar los aciertos de ambos esquemas. Desarrollaremos a continuación esta hipótesis.

En el capítulo V del título XII de la Constitución encuentra desarrollo la regulación de servicios públicos domiciliarios. Junto con los planes de desarrollo, el presupuesto, la distribución de recursos y competencias y la banca central, el tema de servicios públicos conforma la "Constitución Económica" de nuestro ordenamiento. Si atendemos a la forma como se encabezó el capítulo V, De la finalidad social del Estado y de los Servicios Públicos, se concluye que tal aparte de la Constitución es un desarrollo del artículo 334 de la Carta, de acuerdo al cual la intervención del Estado en el área de los servicios públicos se orienta a la racionalización de la economía y a la consecución del bienestar general. De acuerdo con este artículo "La dirección general de la economía estará a cargo del Estado. Este intervendrá, por mandato de la ley, en la explotación de los recursos naturales, en el uso del suelo, en la producción, distribución, utilización y consumo de bienes, y en los servicios públicos y privados, para racionalizar la economía con el fin de conseguir el mejoramiento de la calidad de vida de los habitantes, la distribución equitativa de las oportunidades y los beneficios del desarrollo y la preservación de un ambiente sano" (el subrayado es nuestro). Los artículos correspondientes al título V del Capítulo XII de la Constitución (365 a 370) esbozan la regulación de servicios públicos de una manera genérica, y aunque la Constitución no ofrece una definición de los servicios públicos domiciliarios contenidos en los artículos 367, 368, 369 inc. $2^{\circ}$ y 370, podemos recurrir a la Ley 142 de 1994 para definirlos: "Servicios públicos domiciliarios. Son los servicios de acueducto, alcantarillado, aseo, energía eléctrica, telefonía básica conmutada, telefonía móvil rural y distribución de gas combustible (...)"62.

Una lectura del primer inciso de artículo 365 de la Constitución, el cual es el pilar central de la regulación de servicios públicos, podría llevarnos a la conclusión de que en Colombia la intervención pública en materia de servicios públicos es característica de un Estado de Bienestar. En efecto, según tal inciso "Los servicios públicos son inherentes a la finalidad social del Estado. Es deber del Estado asegurar su prestación a todos los habitantes del territorio." Se trataría de un Estado que para alcanzar sus metas sociales provee de manera paternalista y exclusivista los servicios públicos a los ciudadanos, y al cual además se le asigna el deber de prestarlos de manera

${ }^{62}$ Ley 142 de 1994, artículo 14.21 
eficiente. Sin embargo, en el segundo inciso del mismo artículo se establece lo que algunos autores han denominado la "libre entrada en la prestación de los servicios públicos" ${ }^{63}$. Libre entrada ya que no sólo el Estado, sino los particulares y las comunidades organizadas pueden prestar los servicios públicos sin necesidad de autorización o de negocios jurídicos entre estos y la entidad pública encargada de prestar el servicio ${ }^{64}$. En este punto habríamos dado un súbito giro hacia una concepción de los servicios públicos completamente receptiva al mercado y a la iniciativa privada, muy cercana por demás al modelo neoliberal y de Estado Mínimo. En este sentido el Estado puede prestar -si así lo decide- de forma directa o indirecta los servicios públicos domiciliarios, entrando de esta manera a competir en el mercado con los particulares y las entidades privadas, quienes eventualmente podrían resultar vencedores en el impredecible juego de la libre competencia. Aquí se estaría desarrollando y dándole primacía a lo establecido en el artículo 333 de la Constitución, de acuerdo al cual "La actividad económica y la iniciativa privada son libres, dentro de los límites del bien común. Para su ejercicio, nadie podrá exigir permisos previos ni requisitos, sin autorización de la Ley".

No obstante, en el mismo artículo 365 se establece que “(...) el Estado, en todo caso, mantendrá la regulación, el control y la vigilancia de dichos servicios". De esta manera, aunque el Estado garantiza la libertad de la iniciativa privada en la prestación de servicios públicos, se reserva el derecho de intervenir en este sector a través de la regulación, el control y la vigilancia de dicha actividad económica. Con este modelo se evade la paradoja de un Estado distribuidor de servicios públicos que ahoga la autonomía y la iniciativa privada, pero también la de un mercado de los servicios públicos ajeno y libre de la función reguladora del Estado. Lo que tenemos es un modelo de intervención estatal de rango intermedio, en la medida en que el Estado se limita a regular por medio de normas legales el sector económico de los servicios públicos (art. 365 C.P.), y a controlar y vigilar dicho sector a través de las facultades otorgadas por el ejecutivo a la Superintendencia de Servicios Públicos Domiciliarios (art. 370 C.P.).

La función de regulación estatal en servicios públicos domiciliarios está en cabeza del legislador, a quien según el artículo 365 de la Constitución le corresponde expedir el régimen de los servicios públicos en las siguientes

\footnotetext{
${ }^{63}$ Montaña Plata, A. (2002). El Concepto de Servicio Público en el Derecho Administrativo. Bogotá, Universidad Externado de Colombia., p. 95.

${ }^{64}$ Palacios Mejía, H. (1999). El Derecho de los Servicios Públicos. Bogotá, Derecho Vigente., p. 169.
} 
materias: fijación de competencias y responsabilidades, cobertura, calidad, financiación, régimen tarifario, protección a los usuarios y participación en la gestión y fiscalización de los servicios públicos. Las funciones regulativas se desarrollan, por lo tanto, a través de la actividad legislativa. Por otra parte, las funciones de control y vigilancia, según el artículo 370 de la C.P., están a cargo del Presidente de la República y del organismo de control y vigilancia dependiente del Ejecutivo, esto es, la Superintendencia de Servicios Públicos domiciliarios, la cual fue creada por la Ley 142 de 1994 "(...) como un organismo de carácter técnico, adscrito al Ministerio de Desarrollo Económico, con personería jurídica, autonomía administrativa y patrimonial" ${ }^{65}$.

Podríamos afirmar en síntesis que la regulación de los servicios públicos domiciliarios contenida en la Constitución de 1991 es de carácter finalista, en la medida en que no encuentra fundamento en la naturaleza del sujeto prestador del servicio (sea público o privado), sino en el cumplimiento, por parte del Estado, del fin de prestar eficientemente el servicio a todos los habitantes, ya sea a través de la intervención directa, la delegación o la desconcentración funcional ${ }^{66}$. La Corte Constitucional ha considerado que son éstas las tres formas en que se pueden prestar los servicios públicos domiciliarios. Por una parte, la intervención puede ser directa cuando el servicio sea atendido por un organismo público, delegada cuando el servicio sea dirigido por particulares que atienden su explotación bajo la dirección y control de la administración, y desconcentrada cuando el servicio público sea prestado por un particular, no mediante concesión, sino en desarrollo de la libertad de empresa ${ }^{67}$. Pero aún en este último escenario "(...) no se releva al Estado de su primordial función en la materia cual es, en los términos de la Constitución, la de asegurar que se presten de manera eficiente a todos los habitantes del territorio nacional. ${ }^{68}$ "

El modelo de regulación de los servicios públicos construido en la Constitución colombiana puede entenderse, pues, como un punto intermedio entre el esquema privado de suministro y el esquema estatal-asistencialista.

\footnotetext{
${ }^{65}$ Artículo 76 de la Ley 142 de 1994.

${ }^{66}$ Unijus and Minjusticia (1997). Servicios Públicos Domiciliarios:Calidad de Vida y Construcción del

Estado Social de Derecho. Bogotá, Imprenta Nacional de Colombia., p. 61.

${ }^{67}$ Corte Constitucional. Sentencia T-507 de 1993, (M.P. Alejandro Martínez Caballero).

${ }^{68}$ Corte Constitucional. Sentencia T-306 de 1994, (M.P. Hernando Herrera Vergara).
} 
El esquema privado de suministro local de servicios públicos domiciliarios está asociado en Colombia a la fase de desarrollo urbano (1875-1930), durante la cual los prestadores de estos servicios fueron las empresas privadas (en ocasiones extranjeras) que operaban bajo concesiones otorgadas por los municipios $^{69}$. La escasa o nula capacidad regulatoria del Estado frente a las compañías privadas originó, a principios del siglo $\mathrm{XX}$, una serie de tensiones que se manifestaron en el régimen tarifario y en la conformación de monopolios privados ${ }^{70}$. Este tipo de paradojas le abrió el camino a un esquema centralista y asistencialista en la prestación de servicios públicos domiciliarios, asociado en su primera etapa con la reforma constitucional impulsada por el gobierno de López Pumarejo en 1936, en la cual se estableció que el Estado debía cumplir un papel intervencionista en la economía mediante la dirección general de ésta, la participación económica directa y el fomento a ciertas áreas de la actividad productiva y de regulación ${ }^{71}$. La necesidad de un papel más intervencionista por parte del Estado se acentuó con los problemas de cobertura y financiación en la prestación de servicios públicos domiciliarios. El consecuente fortalecimiento del rol del Estado en los servicios públicos se vio representado en la creación de instituciones como INAGUAS, INSFOPAL y el ICT, las cuales fueron posteriormente fusionadas (1954-1957) en la Corporación Nacional de Servicios Públicos, adscrita a la Presidencia de la República ${ }^{72}$. Pero este modelo, en el cual la inversión privada había perdido progresivamente su importancia, generó graves problemas como la baja capacidad de financiación, la deficiencia en la planeación y la poca expansión que permitían las bajas tarifas, pero sobre todo la ineficiencia, el clientelismo y la corrupción asociada con la alta injerencia que tenía la política local en la dirección de las empresas estatales de servicios públicos domiciliarios ${ }^{73}$. La crisis del modelo estatal-asistencialista alcanzó su fase más crítica durante el denominado "apagón", que aunado a las críticas hechas desde las posiciones neoliberales que progresivamente fueron posicionándose en nichos estratégicos del Estado para impulsar reformas económicas liberalizadoras (especialmente durante los dos últimos años del gobierno de Virgilio Barco, y de forma más evidente y radical durante el de César Gaviria), hacían presagiar el retorno a una prestación privada de los servicios públicos domiciliarios.

\footnotetext{
${ }^{69}$ Unijus and Minjusticia (1997). Servicios Públicos Domiciliarios:Calidad de Vida y Construcción del Estado Social de Derecho. Bogotá, Imprenta Nacional de Colombia., p. 26.

${ }^{70}$ Ibid., p. 26.

${ }^{71}$ Ibid., p. 27.

${ }^{72}$ Ibid., p. 28.

${ }^{73}$ Ibid., p. 29.
} 
Sin embargo, el constituyente de 1991 no dio el paso hacia un modelo privatizador ortodoxo en materia de servicios públicos domiciliarios. Aunque en la Asamblea Constituyente de 1991 se reconocía el argumento de los defensores del Estado Mínimo, según el cual en materia de servicios públicos domiciliarios "(...) ya en los años ochenta, el esquema centralista se agotó en todos los ámbitos de la vida nacional ${ }^{74}$ ", se adoptó el modelo regulador como una solución intermedia al problema de la intervención estatal en esta área de la economía. El diseño de un modelo regulador resulta consecuente debido a que éste se adapta tanto a las exigencias de un Estado Social de Derecho, como a las del libre mercado. En esta medida, la regulación de los servicios públicos domiciliarios aspira a un equilibrio entre la libre competencia y la intervención estatal. En la Asamblea Nacional Constituyente se intentó construir un modelo de economía que "(...) mantuviera la libertad económica dentro de los límites del bien común y la dirección de la economía en cabeza del Estado, como no puede ser de otra forma si se está de acuerdo, como nosotros lo estamos, en que la República de Colombia se defina como un Estado social de derecho (...)." ${ }^{\prime 75}$ Dentro de este gran esquema económico los servicios públicos domiciliarios juegan un papel determinante, ya que "(...) el Estado social y democrático de derecho tiene una concreción técnica en la noción de servicio público"76. En esta medida, la regulación de los servicios públicos proveía suficientes herramientas de direccionamiento del mercado como para asegurar los fines sociales del Estado, pero al mismo tiempo abría campo a la iniciativa privada para que entrara a prestar servicios públicos domiciliarios. La regulación en materia de servicios públicos domiciliarios puede considerarse, en consecuencia, como un satisfactorio acuerdo entre comprensiones maximalistas y minimalistas de la intervención estatal en la economía. Como lo afirmó uno de los más enconados defensores del Estado Mínimo en Colombia al referirse a la regulación en materia de servicios públicos domiciliarios: "La función reguladora, no debe ser entendida como el ejercicio de un intervencionismo entorpecedor de la iniciativa empresarial. En su visión moderna, la regulación es una actividad estatal que fomenta la competencia en aquellas áreas donde existe y es factible; impide el abuso de posiciones de monopolio natural, donde

\footnotetext{
${ }^{74}$ Véase Hommes, Rudolf y otros, Hacia un Nuevo Régimen de Servicios Públicos DomiciliariosExposición de Motivos del Proyecto de Ley 35 de 1992, por el cual se establece el régimen de los servicios públicos domiciliarios. Citado en Ibid., p. 81.

${ }^{75}$ Perry, Serpa y Verano. Proyecto de Acto Reformatorio de la Constitución Política de Colombia No. 59. Citado en Ibid., p. 33.

${ }^{76}$ Corte Constitucional. Sentencia T-540 de 1992, (M.P. Eduardo Cifuentes Muñoz).
} 
esta es ineludible; desregula para eliminar barreras artificiales a la competencia y, finalmente, calibra las diversas áreas de un servicio para impedir prácticas discriminatorias o desleales para el competidor"77.

\section{Regulación mínima y regulación máxima}

El esquema regulatorio de los servicios públicos domiciliarios ha traído un número importante de efectos positivos. La cobertura de buena parte de los servicios públicos domiciliarios, por ejemplo, ha aumentado significativamente durante la última década, la cual corresponde a la implantación del modelo regulador en Colombia ${ }^{78}$. El crecimiento de la cobertura urbana de acueducto pasó de un 82\% en 1985 a cerca de un $95 \%$ en el año 2000, mientras que en el mismo periodo de tiempo la cobertura rural en acueducto pasó de un $11 \%$ a un $44 \%{ }^{79}$. Los indicadores de cobertura urbana de acueducto y alcantarillado, $95 \%$ y $87 \%$ respectivamente, son los segundos más altos de Latinoamérica después de Chile, y resultan comparables a los de países desarrollados como Canadá ${ }^{80}$. Los niveles de cobertura urbana del servicio de aseo se han incrementado notablemente durante esta última década, alcanzando para el año 2000 un nivel cercano al 95\% ${ }^{81}$. Para el año 2000 las cifras de telefonía pública básica conmutada (TPBC) eran alentadoras: en total se contaba con 6.865.140 líneas en servicio, lo que equivalía a una teledensidad de $18,4 \%$, indicador que resulta favorable para Colombia comparado con el promedio latinoamericano, cercano al $13 \%{ }^{82}$.

Sin embargo, los resultados en otras áreas son poco reconfortantes. El sector energético no se ha podido recuperar de la crisis que viene experimentando durante las últimas dos décadas. El proceso de privatización de las empresas de energía eléctrica que se inició a partir de la expedición del

\footnotetext{
${ }^{77}$ Véase Hommes, Rudolf y otros, Hacia un Nuevo Régimen de Servicios Públicos DomiciliariosExposición de Motivos del Proyecto de Ley 35 de 1992, por el cual se establece el régimen de los servicios públicos domiciliarios. Citado en UNIJUS and MINJUSTICIA (1997). Servicios

Públicos Domiciliarios:Calidad de Vida y Construcción del Estado Social de Derecho. Bogotá, Imprenta Nacional de Colombia., p. 81.

${ }^{78}$ Contraloría General de la República, C. G. d. 1. (2002). Colombia: Entre la Exclusión y el Desarrollo-Propuestas Para la Transición al Estado Social del Derecho. Bogotá., p. 238.

${ }^{79}$ Fuente DNP-SSPD. Fuente Ibid., p. 239.

${ }^{80}$ Fuente: Cepis-OPS, Ibid., p. 239.

${ }^{81}$ Ibid., p. 239.

${ }^{82}$ Ibid., p. 240.
} 
Decreto 700 de 1992 no ha tenido los efectos esperados. Pese a que para el año 2000 el sector privado participaba del 62\% de la generación y del 44\% de la distribución de energía, el diagnóstico general de la situación del sector eléctrico resulta crítico: con excepción de los casos de tres empresas (EPM, Codensa y EPSA) las pérdidas financieras de las electrificadotas son muy elevadas ${ }^{83}$. La cobertura total en esta área es también deficiente, alcanzando en el año 2000 apenas un 50,3\% ${ }^{84}$. Los niveles de facturación energética, por su parte, han aumentado significativamente durante la última década. Entre 1998 y 2001 en los estratos 1, 2 y 3, por ejemplo, las tarifas aumentaron en niveles muy superiores a los incrementos del índice de inflación para el mismo periodo ${ }^{85}$. En el sector de acueducto y alcantarillado las tarifas también han aumentado por encima del índice de inflación, y se prevé que para el año 2005 se mantenga esta tendencia ${ }^{86}$. A esto se le añade, en el área de acueducto y alcantarillado, la marcada diferencia en la cobertura del servicio público entre áreas urbanas y rurales.

Algunos autores señalan que el principal obstáculo que enfrenta el marco regulatorio de los servicios públicos domiciliarios, y el cual permitiría explicar buena parte de los problemas de este sector de la economía, reside en la falta de garantías que se ofrece a la libre competencia ${ }^{87}$. Según esta posición existe una contradicción evidente en que, de acuerdo al modelo regulatorio, el Estado reglamente, regule y compita al mismo tiempo en materia de servicios públicos domiciliarios ${ }^{88}$. La propuesta que está a la base de este tipo de posiciones es la de una retirada gradual del Estado de la función reguladora, específicamente de las agencias reguladoras. Aunque con argumentos muchas veces débiles e intuitivos, lo que estos autores buscan mostrar es que la ingerencia política (a través del Ministerio de Hacienda) en las comisiones de regulación de servicios públicos domiciliarios supone una interferencia en la economía que termina haciendo nugatorio el derecho a la libre competencia consagrado en el artículo 333 de la C.P. ${ }^{89}$, y al cual

\footnotetext{
${ }^{83}$ Ibid., p. 270.

${ }^{84}$ Fuente: IPSE y DNP. Ibid., p. 273.

${ }^{85}$ Ibid., p. 278.

${ }^{86}$ Ibid., p. 266.

${ }^{87}$ Véase Garcia, C. A. and L. Villegas (2001). Regulación de los Servicios Públicos:

Redefinición Constitucional del Estado Colombiano. Derecho Constitucional-Perspectivas Críticas.

Bogotá, Observatorio de Jusiticia Constitucional Uniandes-Editorial Legis.

${ }^{88}$ Ibid., p. 131.

${ }^{89}$ Ibid., pp. 130-131.
} 
estos autores dan primacía sobre la función interventora del Estado en economía consagrada en otros apartes de la Constitución. Esta tesis, que podríamos denominar de regulación mínima, sostiene que la libre competencia en el mercado de los servicios públicos domiciliarios no debe ser obstaculizada por la regulación del Estado, ya que a través de tal regulación se presenta una interferencia política y una cooptación de intereses que termina poniendo a los particulares en evidente desventaja frente al Estado (el único sujeto que participa en este mercado con base en reglas de juego que él mismo ha fijado), con lo cual se derrumbarían los pilares de la libre competencia y de la libertad de empresa. Lo que propone en consecuencia la tesis de la regulación mínima es que el Estado se retire de las agencias reguladoras, y por lo tanto de la función reguladora, de modo que se pueda romper con la paradoja de un Estado que regula y compite al mismo tiempo en un mercado que desincentiva abiertamente la participación de los actores privados ${ }^{90}$.

La tesis de la regulación máxima propone, por el contrario, un control estatal exclusivo de la actividad regulatoria, así como una retirada de los actores privados de las agencias reguladoras. Podemos identificar claramente esta tesis en los argumentos que propone a la Corte Constituciona ${ }^{91}$ el demandante de un conjunto de normas relacionadas con servicios públicos domiciliarios $^{92}$, quien sostiene que, de manera inconstitucional, el régimen relativo a las funciones de las comisiones de regulación ha otorgado primacía a la dinámica del mercado sobre los principios sociales característicos de un Estado Social de Derecho. El actor sostiene, por ejemplo, que la Ley 142 de 1994 estableció un marco regulatorio en donde principios como la libre

\footnotetext{
${ }^{90}$ Estas tesis de la regulación mínima no tienen en cuenta que aún en los procesos más agresivos de privatización de los servicios públicos a nivel internacional, los gobiernos han mantenido -O incrementado- sus funciones de regulación en el mercado. El caso de las privatizaciones en Gran Bretaña durante el gobierno Thatcher es paradigmático. Cuando este gobierno privatizó las telecomunicaciones, creo paralelamente una poderosa agencia reguladora, OFTEL. Lo mismo ocurrió con la privatización parcial de los servicios de acueducto y alcantarillado, con la creación por parte de Thatcher de una agencia reguladora, OFWAT. Véase, Parker, C. and J. Braithwaite (2003). Regulation. The Oxford Handbook of Legal Studies. Oxford, Oxford University Press. P. 123.

${ }^{91}$ Sentencia C-150 de 2004 (M.P. Manuel José Cepeda).

${ }^{92}$ El demandante, Humberto de Jesús Longas Londoño, solicita que se declaren inconstitucionales un gran número de artículos de la Ley 142 de 1994; el artículo $1^{\circ}$ de la Ley 286 de 1996; el artículo $2^{\circ}$ y el artículo $3^{\circ}$ de la Ley 632 de 2000; y el parágrafo del artículo 18, el artículo 19 y el artículo 23 de la Ley 689 de 2001.
} 
competencia, la defensa del mercado, la remuneración a los propietarios de las empresas prestadoras de servicios públicos domiciliarios, los cuales son propios de un sistema de mercado y de libre competencia económica, desplazan de manera inconstitucional los principios sociales, de solidaridad y de redistribución consagrados en la Carta en materia de servicios públicos domiciliarios. Esta injustificada subordinación del esquema regulatorio a criterios de eficiencia económica y suficiencia financiera -alega el actor- se ve representada en un régimen tarifario de servicios públicos domiciliarios que obedece a criterios meramente empresariales. A través de este esquema regulador los dueños de las empresas prestadoras de servicios públicos pueden darle primacía a sus intereses particulares por encima de los mandatos establecidos en la Constitución, de acuerdo a los cuales los servicios públicos domiciliarios son inherentes al Estado (art. 364 C.P.), quien deberá prestarlos para asegurar el bienestar general y el mejoramiento de la calidad de vida de la población (art. 366 C.P.). Lo que está detrás del esquema regulador de servicios públicos domiciliarios es, según el demandante, un régimen en el cual el interés público cede ante el privado en tanto la finalidad principal de éste es garantizar el beneficio y el lucro de las empresas prestadoras de servicios públicos. El sistema tarifario en materia de servicios públicos domiciliarios, al estar fundado en la prioridad de los criterios de eficiencia económica sobre los de redistribución equitativa de la riqueza, lleva a que los sectores más pobres de la sociedad encuentren obstáculos muchas veces insalvables para acceder a los servicios públicos domiciliarios, con lo cual se estaría desconociendo la obligación del Estado de intervenir en la economía "para asegurar que todas las personas, en particular las de menores ingresos, tengan acceso efectivo a los bienes y servicios básicos" (art. 334 de la C.P.).

En esta Sentencia (C-150 de 2004) la Corte desestima los argumentos del actor, y decide declarar la exequibilidad de todos los artículos demandados. La Corte considera que el esquema de regulación de servicios públicos domiciliarios sí tiene como uno de sus objetivos el de garantizar la libre competencia y la asignación eficiente de recursos; sin embargo esto no riñe-como argumenta el demandante- con el objetivo principal de la intervención del Estado en economía, el cual es "(...) asegurar la compatibilidad de un mercado eficiente con los principios del Estado social de derecho, dentro de una democracia participativa en la cual los derechos de todos los usuarios sean efectivamente protegidos y garantizados." Para la Corte la intervención del Estado en la economía se hace indispensable frente a las fallas del mercado, las cuales se evidencian en fenómenos como los monopolios, los problemas de información, la oferta limitada y el abuso de la posición dominante, las externalidades y las barreras de ingreso en el mercado. La corrección 
del mercado de los servicios públicos domiciliarios lo realiza el Estado a través de la regulación, y tiene como función principal la de mantener condiciones de competitividad que aseguren la protección de los intereses sociales de equidad y solidaridad consagrados en la Constitución. En consecuencia, sostiene la Corte en este pronunciamiento que "(...) la libertad económica permite también canalizar recursos privados, por la vía del incentivo económico, hacia la promoción de concretos intereses colectivos y la prestación de servicios públicos. En esa posibilidad se aprecia una opción, acogida por el constituyente, para hacer compatibles los intereses privados, que actúan como motor de la actividad económica, con la satisfacción de las necesidades colectivas. Por ello, el constituyente expresamente dispuso la posibilidad de la libre concurrencia en los servicios públicos, los cuales pueden prestarse por el Estado o por los particulares, cada uno en el ámbito que le es propio, el cual, tratándose de estos últimos, no es otro que el de la libertad de empresa y la libre competencia. Sin embargo la Constitución ha previsto, para la preservación de valores superiores, las posibilidad y la necesidad de que el Estado ejerza labores de regulación, vigilancia y control, a través de una serie de instrumentos de intervención con los cuales se controlan y limitan los abusos y deficiencias del mercado. Dicha intervención es mucho más intensa precisamente cuando se abre la posibilidad de que a la prestación de los servicios públicos concurran los particulares".

En síntesis, la tesis de la regulación máxima no puede ser aceptada por la Corte ya que es incapaz de reconocer el objetivo principal perseguido por el Estado al garantizar, a través de la regulación, la libre competencia y el interés de los actores privados en el mercado de los servicios públicos domiciliarios. Tal objetivo no es incentivar el lucro económico de los empresarios privados, sino "orientar el interés privado -como lo es la realización de una actividad empresarial- al desarrollo de funciones socialmente apreciadas".

Consideramos que los argumentos de la Corte contra la tesis de la regulación máxima son acertados y ajustados a los lineamientos constitucionales sobre regulación de servicios públicos domiciliarios. Hemos venido sosteniendo que la regulación en materia de servicios públicos domiciliarios combina características del esquema de regulación mínimo y máximo, con lo cual el constituyente y el legislador quisieron fijar un punto intermedio entre la intervención del Estado en la economía con miras a la consecución del interés social, y la libre competencia de los privados con objeto de asignar eficientemente recursos económicos. Pero si debido a esto resulta inadecuada la tesis de la regulación máxima, también debe concluirse que los argumentos de la regulación mínima deben ser descartados por insuficientes. La 
retirada del Estado de las funciones de regulación resulta tan inconsecuente con el esquema regulatorio en materia de servicios públicos domiciliarios, como la prohibición de que los actores privados intervengan en el mismo.

En esta medida sostenemos que concentrarse exclusivamente en la calidad del ente regulador es una estrategia de investigación poco fructífera. Habíamos dicho anteriormente que la regulación en materia de servicios públicos domiciliarios es de carácter finalista, en tanto no encuentra fundamento en la naturaleza del sujeto prestador del servicio (sea público o privado), sino en el cumplimiento, por parte del Estado, del fin de prestar eficientemente el servicio a todos los habitantes, ya sea a través de la intervención directa, la delegación o la desconcentración funcional ${ }^{93}$. Por lo tanto, si queremos estudiar con mayor éxito la problemática de la regulación de servicios públicos domiciliarios no debemos poner el énfasis metodológico en quién regula, sino en cómo se regula.

Consideramos, por lo tanto, que el estudio del esquema regulatorio sobre servicios públicos domiciliarios debe entrar a analizar fenómenos como la inflación normativa en materia regulatoria, y los efectos reales que tiene la regulación sobre los fenómenos que pretende tratar. La literatura sobre la "crisis del Estado regulador" hace énfasis precisamente en estos factores. No obstante, entre nosotros tales tesis no se han introducido suficientemente en los debates sobre regulación de servicios públicos domiciliarios. Al abordar estos temas buscaremos abrir una nueva y tal vez más promisoria perspectiva para el estudio de estos fenómenos, la cual puede ser puesta en práctica en futuros estudios sobre la materia.

\section{La crisis del Estador Regulador: la juridificación y el trilema regulatorio}

El legislador y los entes de control y vigilancia ejercen sus funciones de regulación a través de una normatividad diseñada para tener un efecto específico en ciertas áreas sociales. La regulación se ejerce, pues, a través de normas jurídicas ${ }^{94}$. En Colombia la intervención del Estado en el mercado de servicios públicos domiciliarios se lleva a cabo por medio de un conjunto

\footnotetext{
${ }^{93}$ Unijus and Minjusticia (1997). Servicios Públicos Domiciliarios:Calidad de Vida y Construcción del Estado Social de Derecho. Bogotá, Imprenta Nacional de Colombia., p. 26.

${ }^{94}$ Cabe aclarar pese a que en Colombia la regulación sobre servicios públicos domiciliarios se ejerce a través de normas, no toda regulación se vale del derecho. Como lo muestran Parker y Braithwaite, hay una gran cantidad de formas de regulación, ya sean formales o informales. El
} 
de normas que emite el Congreso de la República y la Superintendencia de Servicios Públicos Domiciliarios, con objeto de regular este mercado y de obtener por esta vía ciertos efectos relativos a la eficiencia y a la equidad en la prestación de tales servicios. Sin embargo, la regulación no tiene siempre los efectos deseados. Ya hemos dicho que las causas de estas "paradojas regulatorias" no deben buscarse en la naturaleza del ente regulador, sino en la forma en que se regula. La hipótesis que queremos proponer aquí es que una posible explicación de la crisis regulatoria en materia de servicios públicos domiciliarios puede buscarse en los efectos que conlleva el exceso de regulación existente sobre esta materia (juridificación), y en las paradojas que genera este fenómeno en la eficacia, coherencia y equidad de la regulación estatal (trilema regulatorio).

Un repaso a los voluminosos compendios de las normas sobre regulación en materia de servicios públicos domiciliarios ${ }^{95}$ nos lleva a formularnos las siguientes preguntas: ¿que efectos tiene la proliferación de normas regulatorias en la labor desempeñada por los órganos reguladores? ¿Hasta qué punto el exceso de regulación puede hacer menos efectiva la labor regulatoria? ¿En qué medida puede afirmarse que el crecimiento descontrolado de la regulación puede ser un obstáculo para obtener determinados efectos en el área social regulada?

Las tesis sobre la "crisis del Estado regulador" han intentado dar respuesta a estos interrogantes. Una posición bastante extendida en esta literatura sostiene que el modelo de Estado regulador genera un fenómeno de "juridificación" o "hiperinflación normativa", el cual permite explicar la paradoja según la cual entre mayor sea la proliferación de normas regulatorias menores serán los efectos deseados en el área regulada. Estas tesis, las cuales enmarcan la crisis del Estado regulador dentro de las contradicciones del Estado Social de Derecho, parten del supuesto de que este esquema estatal utiliza la regulación jurídica para cumplir con la gran cantidad de deberes

llamado "nuevo estado regulador" puede valerse en su labor regulatoria no sólo de normas jurídicas, sino de normas sociales, de la auto-regulación de los sujetos, del mercado, o de la misma arquitectura. Véase Parker, C. and J. Braithwaite (2003). Regulation. The Oxford Handbook of Legal Studies. Oxford, Oxford University Press. P, 122.

${ }^{95}$ Véase, Superintendencia de Servicios Públicos Domiciliarios, S. d. S. P. (2002). Servicios públicos domiciliarios : régimen básico. Bogotá. Empresas Públicas de Medellin, E. P. d. (2002). Al pie de la norma : servicios publicos domiciliarios. Medellin, Atehortúa, C. (2003). Servicios públicos domiciliarios : legislación y jurisprudencia. Medellín, Biblioteca Jurídica Dike. 
que le son propios. En este sentido, cumplir con las promesas "materiales" del Estado Social de Derecho a través de la regulación jurídica genera disfunciones sistémicas como la "juridificación" y el "trilema regulatorio", las cuales evidencian la incapacidad del Estado Social de Derecho de alcanzar sus objetivos a través de la "hiperregulación". Con objeto de hacer mayor claridad sobre estas posiciones críticas pasamos a sintetizar los principales argumentos de tales tesis.

\section{El concepto de juridificación}

Simitis sostiene que detrás del debate sobre la juridificación se refleja una crítica más amplia al estado intervencionista. Este autor muestra que el paso del estado "contemplativo" al estado "interventor" es el trasfondo sobre el cual empieza a desarrollarse el debate alrededor de la juridificación ${ }^{96}$. Aunque para muchos el término juridificación ${ }^{97}$ hace referencia al "legalismo" y a la "burocratización" típicamente alemana, el fenómeno de la juridificación puede extenderse a los casos de muchos países industrializados y no industrializados. En este sentido podría afirmarse, como lo hace Simitis, que una vez iniciados los procesos de intervención estatal ya no hay alternativa frente al fenómeno de la juridificación ${ }^{98}$. Según Simitis, los procesos de juridificación tienen una fase de reacción y una fase de prevención ${ }^{99}$. En la fase reactiva la intervención del Estado se orienta a dar respuestas puntuales a los problemas generados por procesos de índole económica. En la segunda etapa, las intervenciones del Estado se van integrando en un sistema general dirigido a la regulación a largo plazo del desarrollo social y económico. Prevenir, y no reaccionar, se convierte en la consigna de la intervención estatal. Así, como lo plantea Simitis, en el proceso de juridificación de las relaciones laborales la primera fase consistió en la protección de los trabajadores frente a los despidos masivos bajo el nuevo esquema de una economía industrializada; la segunda avanzó ya no hacia una protección del trabajo, sino hacia una promoción y fomento del empleo ${ }^{100}$.

\footnotetext{
${ }^{96}$ Simitis, S. (1987). Juridification and Labor Relations. Juridification of the Social Spheres. Berlín, Walter de Gruyter.

${ }^{97}$ Según Teubner, el término alemán "Verrechtlichung" es una construcción gramatical tan desagradable y extraña como la misma realidad que describe. Véase, Teubner, G. Ibid.The Transformation of Law in the Welfare State. La traducción al inglés del término alemán es "juridification". Consideramos que la traducción más adecuada al español es "juridificación”. ${ }^{98}$ Simitis, S. Ibid.Juridification and Labor Relations.

${ }^{99}$ Ibid.
} 
Los procesos de instauración de un Estado Social de Derecho implican un creciente proceso de intervención estatal, el cual se ve reflejado en un abrumador flujo de normas ${ }^{101}$. El Estado se vale de la producción legislativa para injerir directamente en la sociedad ${ }^{102}$, lo cual tiene como consecuencia el surgimiento del fenómeno de la juridificación. En este sentido la juridificación puede ser entendida como un proceso de "inflación legislativa" ${ }^{103}$, de "explosión legal", de "polución legal", o de "burocratización del mundo" ${ }^{104}$. Como lo sostiene Holtschneider, el fenómeno de la juridificación puede ser visto como un (i) crecimiento del derecho positivizado, como (ii) un crecimiento de las áreas sociales normativizadas, y como (iii) una mayor especificidad de las normas ${ }^{105}$. Para este autor, la causa primaria de este fenómeno es el surgimiento y consolidación del Estado Social de Derecho. En tal coyuntura histórica se hacía necesaria una instrumentalización del sistema jurídico con objeto de cumplir, por un lado, con las exigencias de una sociedad industrializada que para mantener los gigantescos procesos de producción ya no podía contar con los mecanismos de autorregulación tradicionales tales como la familia, la iglesia y la moral; por otra parte, las casi incontables tareas a nivel administrativo, económico y social, impuestas por el esquema de Estado Social de Derecho hacían indispensable la reestructuración del derecho como instrumento de intervención, regulación y control $^{106}$.

Sin embargo, las teorías sobre la juridificación no sólo se encargan de analizar los procesos de inflación normativa. Centrándose únicamente en

${ }^{100}$ Ibid.

${ }^{101}$ El concepto «flujo de normas » equivale al utilizado en la bibliografía alemana sobre juridificación, "Normenflut". Véase, Teubner, G. (1990). Verrechtlichung - ein ultrazyklisches Geschehen. Frankfurt, Humboldt.

${ }^{102}$ Aunque las leyes son el vehículo más adecuado para la juridificación, en el análisis de los fenómenos de juridificación también hay que tener en cuenta las sentencias, los decretos y las medidas administrativas. No se trata únicamente de un proceso de positivización, sino de densificación del derecho en general. Véase, Simitis, S. (1987). Juridification and Labor Relations. Juridification of the Social Spheres. Berlín, Walter de Gruyter.

${ }^{103}$ Holtschneider, R. (1991). Normenflut und Rechtsversagen. Baden-Baden, Nomos Recht. ${ }^{104}$ Teubner, G. (1987). The Transformation of Law in the Welfare State. Juridification of the Social Spheres. Berlín, Walter de Gruyter.

${ }^{105}$ Holtschneider, R. (1991). Normenflut und Rechtsversagen. Baden-Baden, Nomos Recht.

${ }^{106}$ Ibid. 
este aspecto cuantitativo de la juridificación, los análisis se concentrarían en el crecimiento de lo que Baker ha llamado ingeniosamente Producto Legal Bruto -Gross Legal Product- ${ }^{107}$. Se trataría entonces de averiguar qué tanto ha crecido el producto legislativo a lo largo de los años, y de estimar en consecuencia el impacto que esto tiene para la "racionalidad" del derecho. Holtschneider estima, por ejemplo, que en 1910 las normas sociales en Alemania equivalían a un 10\% del total de la legislación; para 1991 la proporción había aumentado a casi un $40 \%{ }^{108}$. Partiendo de este estimado, se trataría entonces de iniciar procesos de desregulación para solucionar el problema de la "hiperinflación" normativa en este campo.

Sin embargo, el aspecto cuantitativo de la juridificación no es el más fructífero del análisis ${ }^{109}$. Como lo sostiene Teubner, no todos los fenómenos de proliferación de normas son procesos de juridificación ${ }^{110}$. Para este autor, se puede hablar de jurdificación en estricto sentido cuando este fenómeno se identifica con la crisis del derecho regulatorio dentro del Estado Social de Derecho, según la cual el derecho está tanto politizado como socializa$\mathrm{do}^{111}$. Los análisis de juridificación no se preguntan únicamente por el creci-

\footnotetext{
${ }^{107}$ Baker sostiene que es virtualmente imposible medir qué tantas leyes se producen anualmente en los Estados Unidos. Para Baker, el hecho de que McDonald's haya renunciado en 1994 a medir qué tantas hamburguesas se producían en sus restaurantes, puede sugerir que en derecho también tengamos que renunciar a la tarea de cuantificar el número de leyes. Afirma Baker: "Until now, no one has stopped to measure just how much law there is in the United States. The fact that McDonald's gave up trying to count hamburgers ("over 100 billion served") back in 1994 may suggest the impossibility of such an accounting. But I thought it might be interesting, and perhaps revealing, to attempt to estimate how much law we produce annually—-the "Gross Legal Product" or "GLP." While I was at it, I tried to guesstimate how much law has accumulated over our Nation's two hundred years—what we might call the "Known Law Reserve"- a la the figures OPEC publishes, and maybe as accurate. Like coal, oil, and natural gas, which accumulate in fields and deposits, our laws accumulate in law libraries. But these book depositories simply cannot expand their capacity fast enough to keep up with the output of lawmakers. A librarian will tell you that it is simply impossible for any law library to collect all the legal publications that are produced annually in the United States. It is in these library collections that law professors, lawyers, and judges mine the law. And law libraries are the best place to attempt to catch the ineffable." Véase, Baker, T. E. (1997). "Tyrannous Lex." Iowa Law Review 82 Iowa L. Rev. 689.

${ }^{108}$ Holtschneider, R. (1991). Normenflut und Rechtsversagen. Baden-Baden, Nomos Recht.

${ }^{109}$ Voigt, R. (1983). Verrechtlichung und Entrechtlichung im Kontext der Diskussion um den Wohlfartsstaat. Gegentendenzen zur Verrechtlichung. W. Verlag. Opladen.

${ }^{110}$ Teubner, G. (1987). Juridification-Concepts, Aspects, Limits, Solutions. Juridification of the Social Spheres. Berlín, Walter de Gruyter.
} 
miento de la masa legislativa en una materia determinada, sino por la expropiación del conflicto en un área social por parte del derecho formal ${ }^{112}$. De esta manera el análisis cualitativo de la juridificación debe tener en cuenta no sólo los límites al crecimiento de la regulación jurídica, sino las consecuencias que tiene en el plano individual y social el proceso de juridificación. Holtschneider sostiene que en los estudios de juridificación que asumen un enfoque cualitativo, se abordan fenómenos a nivel individual tales como (1) la burocratización de la vida del individuo, (2) las dificultades que tiene el individuo para abordar el derecho debido a la gran cantidad de normas, (3) el impacto que tiene en el individuo la mala calidad de las normas, y a nivel social aspectos tales como (1) la falta de funcionalidad del derecho y (2) la relación contraproducente entre derecho y sociedad ${ }^{113}$.

Los análisis sobre la juridificación comparten, en síntesis, una posición crítica ante los efectos adversos que tiene la proliferación de normas sobre los individuos y sobre la sociedad en conjunto. La crítica a los procesos de juridificación debe entenderse dentro del marco de una crítica general a la intervención estatal en áreas sociales que antes no se encontraban reguladas. Tal intervención es entendida como producto de las exigencias del modelo regulador del Estado Social de Derecho y del modelo de una sociedad industrializada y tecnologizada, los cuales utilizan al derecho como instrumento de intervención en la sociedad. Como lo sostiene Zacher, las teorías de la juridificación comparten el argumento según el cual, en las sociedades con esquemas constitucionales de Estado Social de Derecho, la regulación legal ha proliferado y se ha movido a áreas que no puede o no debe cubrir. Según estas teorías, los procesos de juridificación se presentan cuando conjuntos de regulaciones, instituciones y métodos legales abandonan el territorio "propio" del derecho y se desplazan a un terreno social ajeno ${ }^{114}$.

\section{El Trilema regulatorio}

Según Luhmann, el fenómeno de la juridificación debe entenderse como una crisis en las relaciones entre el sistema político y el sistema jurídico. Para Luhmann, los procesos autopoiéticos de ambos subsistemas y su acopla-

111 Ibid.

112 Ibid.

113 Holtschneider, R. (1991). Normenflut und Rechtsversagen. Baden-Baden, Nomos Recht.

114 Zacher, H. F. (1987). Juridification in the Field of Social Law. Juridification of the Social

Spheres. Berlín, Walter de Gruyter. 
miento estructural a través de la Constitución se ven claramente amenazados bajo el esquema de Estado Social de Derecho. Esto ya que en el Estado Social de Derecho las presiones que ejerce el sistema político sobre el jurídico son de tal magnitud que terminan por imponerle al derecho códigos propios de la política. Como en Habermas, en la teoría autopoiética de Luhmann la instrumentalización del derecho por parte del sistema político resulta en una generación de profundas disfunciones sistémicas, las cuales se ven reflejadas en el proceso de juridificación.

Para Luhmann, la desintegración del proceso autopoiético se produce con la irrupción de un código externo en la programación interna del sistema. Según este autor, los mecanismos de acoplamiento estructural cumplen precisamente con la función de evitar este resultado. Gracias ellos los sistemas pueden abrirse cognitivamente a las perturbaciones de otros sistemas externos, al mismo tiempo que mantienen intacto su código operativo. La Constitución, por ejemplo, se encarga de acoplar las estructuras del sistema jurídico y político de modo que sus perturbaciones mutuas puedan ser "compensadas" en cada sistema a través de sus códigos particulares. Ambos sistemas pueden enviarse asimetrías e irritaciones a través del canal de "intercambio doble", sin que por ello interrumpan o concluyan su proceso autopoiético. Cierre normativo y apertura cognitiva se producen, por obra de tales acoplamientos, como dos procesos paralelos y armónicos que garantizan la reproducción del ciclo autopoiético.

No obstante, según Luhmann las presiones que experimenta el derecho por parte de subsistemas como la política y la economía en el Estado Social de Derecho no son siempre resueltos a través de un óptimo acoplamiento estructural. Algunas decisiones del sistema jurídico son comúnmente activadas por criterios externos de policy o eficiencia que, pese a ser traducidos y decididos con el uso del código legal/ilegal, generan un amplio campo de incertidumbre judicial que podría dar pie a que parámetros de oportunidad política o utilidad económica logren instrumentalizar el derecho para sus propios fines ${ }^{115}$.

$\mathrm{Al}$ interior del sistema jurídico se presentan, según Luhmann, "símbolos de stress", los cuales se producen como una forma de respuesta inmunológica a las perturbaciones ambientales que no pueden ser compensadas exitosamente $^{116}$. Estos símbolos de cansancio son sobre todo evidentes en las

${ }^{115}$ Teubner, G. (1989)._Recht als Autopoietisches System. Frankfurt, Suhrkamp. 
irritaciones que soporta el derecho por parte de la política. De acuerdo con Luhmann, con la evolución del constitucionalismo clásico hacia el Estado Social de Derecho el sistema jurídico debe abrirse a un sinnúmero de perturbaciones provenientes del sistema político, las cuales han terminado por poner en peligro el cierre normativo del sistema ${ }^{117}$. Pese a lo que se afirma comúnmente, no es en las influencias o inclinaciones políticas de los jueces en donde ha de estudiarse el acoplamiento estructural fallido entre derecho y política, sino en el fenómeno del Estado Social de Derecho, y más precisamente en el fenómeno de la juridificación ${ }^{118}$. Es allí en donde se hace más claro el "stress" del sistema legal que amenaza con interrumpir su proceso autopoiético.

Tanto para Luhmann como para Teubner la juridificación puede ser entendida como un reflejo de los desórdenes que amenazan a los sistemas jurídicos ${ }^{119}$. Teubner afirma que los subsistemas del derecho, la vida social y la política son autónomos y auto-referentes, por lo que no pueden influenciarse directamente, excepto dentro de los límites de los acoplamientos estructurales, límites que cuando son excedidos causan la "juridificación" ${ }^{20}$. Es esto precisamente lo que sucede en la crisis regulatoria del Estado Social de Derecho.

Del mismo modo que para Habermas, para Luhmann y Teubner los procesos de juridificación deben entenderse, pues, dentro del marco de la crisis regulatoria del Estado Social de Derecho. Bajo este esquema estatal el sistema político recarga de tareas al sistema jurídico a tal grado que termina por romper el proceso autopoiético del último, así como el acoplamiento estructural óptimo entre derecho y política. La instrumentalización política del derecho es, para Teubner, lo que propicia los fenómenos de juridificación. Según este autor, la juridificación se expresa en lo que él denomina el "trilema regulatorio", el cual se puede sintetizar de la siguiente manera. La crisis regulatoria del Estado Social de Derecho, la cual se expresa en el fenómeno de la juridificación, produce (1) un problema de indeferencia mutua entre el sistema político y el jurídico, (2) un problema de desintegración social a

\footnotetext{
${ }^{116}$ Luhmann, N. (1986). "Die Codierung des Rechtsystems." Rechtstheorie 19.

${ }^{117}$ Luhmann, N. (1993). Das Recht der Gesellschaft. Frankfurt, Suhrkamp.

${ }^{118}$ Luhmann, N. (1986). "Die Codierung des Rechtsystems.” Rechtstheorie 19.

${ }^{119}$ Bercusson, B. (1987). Juridfication and Disorder. Juridification of the Social Spheres. Berlín,

Walter de Gruyter.

${ }^{120}$ Ibid.
} 
través del derecho, (3) un problema de desintegración legal a través de la sociedad $^{121}$.

Con la juridificación se produce indiferencia mutua ya que las señales del legislador se desvanecen en la pantalla interna del sistema legal. Debido a la inflación normativa no hay premisas legislativas para seleccionar por parte del sistema legal. Es por esto según Teubner que buena parte de las reformas políticas y los mandatos regulatorios nunca llegan a la sociedad, en la medida en que desaparecen una vez se traducen al derecho. Con la juridificación también se produce una desintegración social a través del derecho ya que se presenta una "colonización del mundo de la vida" por parte del sistema jurídico. La subsunción legal y los procedimientos burocráticos llevan a que problemas de subsistemas ajenos al derecho sean tratados a través de "violentas abstracciones" jurídicas. Según Teubner, en los procesos de jurididificación el derecho interviene en situaciones autoregulatorias de otros sistemas sociales de una forma que pone en peligro las mismas condiciones de auto-reproducción autopoiética de tales sistemas. Por último, con la juridificación se produce una desintegración legal a través de la sociedad, en la medida en que el mismo sistema jurídico alcanza un límite crítico en su efectividad debido a las incontables tareas que le asigna el sistema político en el esquema de ESD. En términos de Luhmann, las distintas velocidades del sistema político y legal pueden recargar al último hasta el punto de romper con su autonomía ${ }^{122}$. El sistema político asigna una gran cantidad de tareas al sistema jurídico, las cuales se espera sean cumplidas con la celeridad y el "repentismo" propios del primero. Al no poder cumplir el sistema jurídico con el tipo de tareas que le asigna el sistema político bajo el esquema de ESD, el derecho entra en una fase de eficacia simbólica y de desintegración de su legitimidad.

Como lo muestran Parker y Braithwaite, el trilema regulatorio planteado por Teubner puede traducirse en los siguientes elementos: efectividad, equidad y coherencia ${ }^{123}$. De acuerdo con Teubner la crisis del Estado regulador se manifiesta en un trilema de acuerdo al cual, la regulación o (1) resulta irrelevante en el área social que pretende regular, o (2) produce efectos desintegradores en el área social que pretende regular, o (3) produce efectos

\footnotetext{
${ }^{121}$ Teubner, G. Ibid.Juridification-Concepts, Aspects, Limits, Solutions.

${ }^{122}$ Ibid.

${ }^{123}$ Parker, C. and J. Braithwaite (2003). Regulation. The Oxford Handbook of Legal Studies.

Oxford, Oxford University Press.pp. 126-129.
} 
desintegradores en el propio sistema jurídico ${ }^{124}$. En el primer eje de este trilema el ente regulador se enfrenta a tal hiperinflación de premisas normativas, que le impiden seleccionar confiablemente un conjunto de medidas regulatorias que tengan los efectos esperados en el área social regulada. De este modo las medida regulatorias resultan insignificantes e ineficaces una vez implementadas. La acumulación de este tipo de medidas genera un área regulada completamente ineficaz. De acuerdo al segundo eje del trilema, pese a que las medidas regulatorias eventualmente pueden resultar eficaces en términos económicos, no logran integrarse a las prácticas y normas sociales sobre las cuales intervienen. Así, estudios de sociología jurídica-Cotterrell y Selznick han evidenciado que regulación legal aparentemente efectiva, pero que no ha integrado prácticas y normas sociales, termina siendo contraproducente en términos de equidad y justicia ${ }^{125}$. Aquí se produce una brecha insalvable entre expectativas sociales-normativas y expectativas regulatorias, la cual puede conducir a que los sujetos sobre los cuales se aplica la regulación terminen eludiéndola o desconociéndola. Por último, el tercer eje del trilema señala cómo el sistema jurídico que no es eficaz y que no cumple con condiciones de equidad, corre peligro de desintegrarse internamente ante las exigencias en materia regulatoria provenientes del sistema político. El sistema jurídico sigue produciendo regulación pese a su ineficacia y a su inequidad; el resultado de esto es la entrada del esquema regulador en una fase meramente simbólica, la cual no puede estructurarse coherentemente en el entramado general del sistema legal.

La crisis regulatoria de los servicios públicos domiciliarios: hacia una nueva agenda de investigación

¿Se presenta el fenómeno de hiperinflación normativa (juridificación) en la regulación de servicios públicos domiciliarios en Colombia, lo cual llevaría a que la regulación resulte ineficaz, inequitativa e incoherente (trilema regulatorio)?

Partiendo del hecho de que al momento no disponemos en Colombia de bibliografía especializada para poner a prueba estas intuiciones sobre la juridificación y el trilema regulatorio, la estrategia investigativa podría consistir, entonces, en hacer un recuento cuantitativo del Producto Legal Bruto (PLB) de la regulación sobre servicios públicos domiciliarios. El primer pro-

\footnotetext{
${ }^{124}$ Ibid.
}

125 Ibid. 
blema consistiría en la metodología cuantitativa para calcular el PLB. ¿Con respecto a qué se puede decir que hay muy poca o demasiada regulación en esta materia? Como anotábamos anteriormente, una mirada a los compendios de normatividad sobre regulación en servicios públicos domiciliarios parecería indicar que, en efecto, hay una voluminosa producción normativa en esta área. Sin embargo, buena parte de esta regulación es técnica, por lo que no podríamos afirmar si es innecesaria o no. Pero suponiendo que un estudio sobre legislación internacional comparada nos muestre que en Colombia la producción legislativa en materia de regulación sobre servicios públicos domiciliarios es excesivamente alta, ipodríamos probar con estos datos que hay un problema de juridificación en esta área? No necesariamente. Sabemos que no todos los fenómenos de inflación normativa constituyen fenómenos de juridificación.

Mostrar que la regulación en servicios públicos domiciliarios presenta síntomas claros de juridificación, y que en consecuencia se enfrenta a un trilema regulatorio, parecería pues una agenda de investigación demasiado ardua e incierta. Consideramos que un análisis cuantitativo de la juridificación, centrado en el análisis del número de normas y en el efecto que tiene esto sobre los resultados de la regulación, es en efecto poco promisorio. Sin embargo, sostenemos que una estrategia investigativa que fije su atención en la forma cómo regulan los operadores, en los efectos que puede tener la inflación regulatoria en la práctica de los operadores, y en la medida en que tales efectos pueden influir en que los resultados de la regulación sean ineficaces, inequitativos e incoherentes, sí constituye efectivamente una agenda de investigación provechosa.

- La visión del operador.

Proponemos orientar la investigación sobre la crisis regulatoria en el área de servicios públicos domiciliarios hacia las siguientes preguntas: ¿Consideran los operadores que enfrentan una regulación excesiva en esta área? Y en el caso de que sea así, icuáles son según ellos los efectos en materia de eficacia, equidad y coherencia que conlleva el fenómeno de la inflación regulativa? Responder afirmativa o negativamente a estas preguntas conllevaría un cambio notable y necesario en las metodologías de investigación sobre la materia. Esto ya que tomaríamos distancia de los estudios estrictamente legalistas, que abordan la regulación como un problema de "derecho en los libros", y no como un problema de "derecho en la práctica". Aunque de manera ciertamente tardía en el área de la regulación, estaríamos dando en nuestros estudios jurídicos el paso que Lewellyn proponía en un célebre artículo de $1930^{126}$, en el cual el autor estadounidense propugnaba por un 
análisis del derecho capaz de dar cuenta de la "conducta" de los operadores. Una buena teoría de la regulación -afirma Adler- se orienta a predecir cuáles serán los resultados regulatorios, a partir de suposiciones sobre la motivación y las creencias humanas"127. En este sentido, nuestras investigaciones se deben orientar a predecir cómo, y con base en qué, toman decisiones sobre regulación los operadores. Determinar si se presenta un fenómeno de juridificación, pues, hace indispensable que el investigador fije su atención en la forma como se regula, en los problemas que enfrentan esta actividad, y en síntesis, en la visión que tiene el operador sobre la labor de regulación. Sólo atendiendo a la práctica de la regulación y a las decisiones de los sujetos involucrados en ésta, podremos determinar si se presenta una hiperinflación regulatoria, y si tal fenómeno tiene efectos negativos en la eficacia, equidad y coherencia de los resultados de la regulación. En este artículo hemos presentado las tesis de la juridificación y del "trilema regulatorio" como hipótesis metodologícas que permitirían explicar la crisis regulatoria. Sin embargo, para poner a prueba tales hipótesis resulta necesario ir de las teorías sobre la regulación hacia la práctica regulatoria. Es aquí donde las metodologías investigativas que brindan las ciencias sociales y la sociología jurídica resultan de vital importancia para la agenda. Aplicar tales metodologías supondría un giro radical y necesario para los estudios jurídicos sobre la crisis regulatoria en materia de servicios públicos.

- Estado Social de Derecho y presiones sistémicas.

Hemos sostenido que los análisis cuantitativos deben estar acompañados por análisis cualitativos, en donde se muestre que la inflación normativa obedece a una presión excesiva que ejerce el sistema político sobre el jurídico dentro del esquema de Estado Social de Derecho. Una vez hecho este análisis, tendríamos que demostrar cómo el fenómeno de juridificación lleva a que la regulación en servicios públicos domiciliarios tienda a ser inefi$\mathrm{caz}$, inequitativa e incoherente.

De este modo, analizar la regulación bajo estas hipótesis significa superar los análisis meramente legalistas sobre la materia, en la medida en que el investigador debe abordar preguntas como las siguientes: ibajo el esquema actual de Estado Social de Derecho en Colombia recibe el sistema jurídico

\footnotetext{
${ }^{126}$ Llewellyn, K. (1930). "A Realistic Jurisprudence - The Next Step." 30 Columbia Law Review 431.

${ }^{127}$ Adler, M. (2000). "Beyond Efficiency and Procedure: A Welfarist Theory of Regulation." 28 Fla. St. U.L. Rev. 241.
} 
una carga desmedida por parte del sistema político, el cual le exige que concrete sus promesas materiales a través, por ejemplo, de la regulación sobre servicios públicos domiciliarios? ¿Obedece el problema de la inflación regulatoria a un fenómeno de eficacia simbólica del derecho, en tanto la profusión de normas regulatorias podría considerarse directamente proporcional a la ineficacia social de la regulación? ¿En qué medida los efectos del fenómeno de la juridificación generan desintegración social y deslegitimación de los mecanismos de regulación propios de un Estado Social de Derecho? ¿Qué tipo de efectos desintegradores tiene la juridificación y el trilema regulatorio sobre el propio sistema jurídico? ¿Cómo se conectan los efectos desintegradores en la sociedad y en el sistema jurídico con la ineficacia de la regulación? ¿Cómo hacer más eficaz la regulación?

Consideramos que las anteriores preguntas son válidas y urgentes. La agenda de investigación que proponemos en este ensayo, a diferencia de los análisis meramente legalistas, contaría con un equipamiento teórico suficiente para abordarlas.

- Claridad sobre los procesos de desregulación.

Podría afirmarse que si nuestra agenda de investigación probara que existe un fenómeno de juridificación y de "trilema regulatorio", la estrategia inmediata a adoptar sería la de la desregulación. La escuela de Análisis Económico del Derecho, sostiene Posner, ha mostrado cómo en muchas áreas de la economía la regulación ha tenido efectos perversos y contradictorios ${ }^{128}$. No hay número de la prestigiosa revista Law and Economics, argumenta Sunstein, que no contenga argumentos contundentes contra la regulación y a favor de la desregulación de muchas áreas de la economía ${ }^{129}$. Sunstein afirma que en muchos casos la regulación más estricta y draconiana, la cual estaba destinada a dirigir cierta área de la economía en particular, ha tenido el efecto absolutamente contradictorio de hacer menos regulada y vigilada tal área (tal es el caso de la regulación laboral sobre el salario mínimo en los Estados Unidos) ${ }^{130}$. En síntesis, puede afirmarse que el movimiento de la desregulación se ha propuesto echar por el suelo muchas de las ortodoxias de la regulación, mostrando a través de estudios empíricos, por ejemplo, que muchos merca-

\footnotetext{
${ }^{128}$ Posner, R. (2004) . "Law and Economics in Common-Law, Civil-Law, and Developing Nations." Ratio Juris 17 (No. 1).

${ }^{129}$ Sunstein, C. (1990). After the Rights Revolution-Reconceiving the Regulatory State. Cambridge, Harvard University Press. P. 48.

${ }^{130}$ Ibid., P. 34.
} 
dos están sujetos a economías de escala no pueden ser regulados a través de métodos convencionales ${ }^{131}$.

Sin embargo, el camino entre la juridificación y la desregulación no es de ninguna manera directo. Si a través de análisis como los que proponemos en este ensayo se probara que en efecto se presenta un problema de juridificación en materia de servicios públicos domiciliarios, la solución a este fenómeno no sería necesariamente la de desregular. Hemos mostrado que en muchas áreas del mercado simplemente no podemos renunciar a la regulación; devolver a las manos invisibles del mercado -a través de la desregulación- las funciones desempeñadas por el Estado en materia de regulación, control y vigilancia, podría conllevar traumáticos efectos sociales. La solución podría estar en regular de manera más efectiva, equitativa y coherente; no necesariamente en desregular. Pero si a través de nuestra estrategia de investigación se muestra que el estado debe retirarse de cierta área del mercado, y que por lo tanto se debe desregular, contaremos con un respaldo teórico y empírico que hará más acertadas las estrategias sobre políticas públicas de desregulación.

\section{- La Necesidad de Mejores Estrategias de Regulación}

Consideramos que la agenda de investigación que hemos propuesto en este ensayo, pese a que supone que la regulación es una necesidad en muchas áreas del mercado, parte del hecho de que las estrategias de regulación pueden ser más eficaces, equitativas y coherentes. Al orientarse al "cómo" de la regulación, puede servir como herramienta operativa para mejorar la indispensable labor de regulación en Colombia.

Bibliografía

E. Bailey, et al. (Spring, 1984.). "Deregulation and the Theory of Contestable Markets."

Yale J. on Reg. 111.

Ackerman, B. and A. Alstott (1999). The Stakeholder Society. New Haven, Yale University Press.

Adler, M. (2000). "Beyond Efficiency and Procedure: A Welfarist Theory of Regulation." 28 Fla. St. U.L. Rev. 241.

Atehortúa, C. (2003). Servicios públicos domiciliarios : legislación y jurispru-

${ }^{131}$, E. Bailey, et al. (Spring, 1984.). "Deregulation and the Theory of Contestable Markets."

Yale J. on Reg. 111. 
dencia. Medellín, Biblioteca Jurídica Dike.

Baker, T. E. (1997). "Tyrannous Lex.” Iowa Law Review 82 Iowa L. Rev. 689.

Baxter, H. (2002). "System and Lifeworld in Habermas's Theory of Law." Cardozo Law Review 23 Cardozo L. Rev. 473.

Bercusson, B. (1987). Juridfication and Disorder. Juridification of the Social Spheres. Berlín, Walter de Gruyter.

Biersteker, T. (1992). The Logic and Unfulfilled Promise of Privatization in Developing Countries. State and Market in Development. London, Lynne Riener.

Bruton, H. J. (1992). International Aspects of the Role of Government in Economic Development. State and Market in Development. London, Lynne Rienner.

Domiciliarios, S. d. S. P. (2002). Servicios públicos domiciliarios : régimen básico. Bogotá.

Garcia, C. A. and L. Villegas (2001). Regulación de los Servicios Públicos: Redefinición Constitucional del Estado Colombiano. Derecho Constitucional-Perspectivas Críticas. Bogotá, Observatorio de Jusiticia Constitucional Uniandes-Editorial Legis.

Habermas, J. (1987). Law as Medium and Law as Institution. Juridification of the Social Spheres. Berlín, Walter de Gruyter.

Habermas, J. (1988). Teoría de la Acción Comunicativa. Madrid, Taurus.

Habermas, J. (1996). "Paradigms of Law." Cardozo Law Review 17 Cardozo L. Rev. 771.

Holtschneider, R. (1991). Normenflut und Rechtsversagen. Baden-Baden, Nomos Recht.

Kirchheimer, O. (1961). Political Justice, Princeton University Press.

Kohler, G. (1987). Verrechtlichung und Verantwortung, Themen einer Epochenschwelle. Verrechtlichung und Verantwortung. Stuttgart, Haupt.

Llewellyn, K. (1930). "A Realistic Jurisprudence - The Next Step." 30 Columbia Law Review 431.

Luhmann, N. (1986). "Die Codierung des Rechtsystems." RECHTSTHEORIE 19.

Luhmann, N. (1993). Das Recht der Gesellschaft. Frankfurt, Suhrkamp.

Empresas Públicas de Medellin (2002). Al pie de la norma : servicios publicos domiciliarios. Medellin.

Montaña Plata, A. (2002). El Concepto de Servicio Público en el Derecho Administrativo. Bogotá, Universidad Externado de Colombia.

Niehans, J. (1990). A History of Economic Theory. Baltimore, The Johns Hopkins University Press.

Offe, C. (1985). Contradictions of the Welfare State. Cambridge, The MIT 
Press.

Palacios Mejía, H. (1999). El Derecho de los Servicios Públicos. Bogotá, Derecho Vigente.

Parker, C. and J. Braithwaite (2003). Regulation. The Oxford Handbook of Legal Studies. Oxford, Oxford University Press.

Posner, R. (1992). Economic Analysis of Law. Boston, Little, Brown and Company.

Posner, R. (2004). "Law and Economics in Common-Law, Civil-Law, and Developing Nations." Ratio Juris 17 (No. 1).

Contraloría General de la República (2002). Colombia: Entre la Exclusión y el Desarrollo-Propuestas Para la Transición al Estado Social del Derecho. Bogotá.

Simitis, S. (1987). Juridification and Labor Relations. Juridification of the Social Spheres. Berlín, Walter de Gruyter.

Spulber, D. F. (1989). Regulation and Markets. Cambridge, The MIT Press.

Streeten, P. P. (1992). Against Minimalism. State and Market Development. London, Lynne Rienner Publishers.

Sunstein, C. (1990). After the Rights Revolution-Reconceiving the Regulatory State. Cambridge, Harvard University Press.

Sunstein, C. (1997). Free Markets and Social Justice. New York, Oxford University Press.

Teubner, G. (1987). Juridification-Concepts, Aspects, Limits, Solutions. Juridification of the Social Spheres. Berlín, Walter de Gruyter.

Teubner, G. (1987). The Transformation of Law in the Welfare State. Juridification of the Social Spheres. Berlín, Walter de Gruyter.

Teubner, G. (1989). Recht als Autopoietisches System. Frankfurt, Suhrkamp.

Teubner, G. (1990). Verrechtlichung - ein ultrazyklisches Geschehen. Frankfurt, Humboldt.

UNIJUS and MINJUSTICIA (1997). Servicios Públicos Domiciliarios:Calidad de Vida y Construcción del Estado Social de Derecho. Bogotá, Imprenta Nacional de Colombia.

Van Parijs, P. ( 1995). Real Freedom for All. What (if anything) Can Justify Capitalism?, Oxford University Press.

Voigt, R. (1983). Verrechtlichung und Entrechtlichung im Kontext der Diskussion um den Wohlfartsstaat. Gegentendenzen zur Verrechtlichung. W. Verlag. Opladen.

Zacher, H. F. (1987). Juridification in the Field of Social Law. Juridification of the Social Spheres. Berlín, Walter de Gruyter. 
